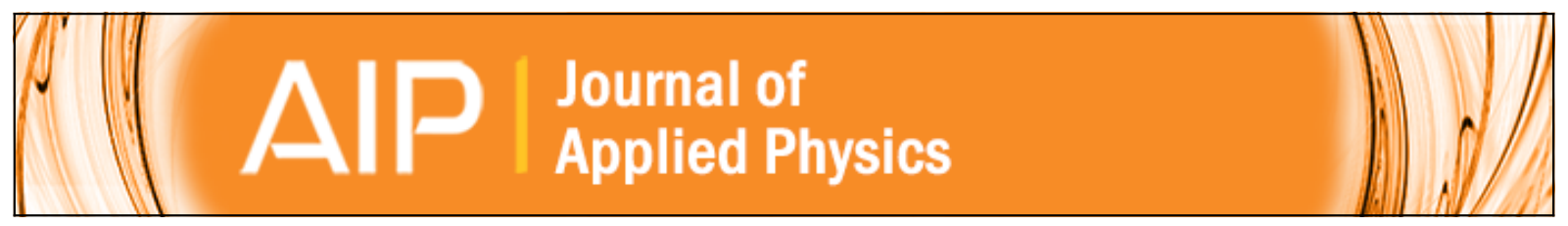

Dynamics of Tm-Ho energy transfer and deactivation of the $3 \mathrm{~F} 4$ low level of thulium in fluorozirconate glasses

L. D. da Vila, L. Gomes, L. V. G. Tarelho, S. J. L. Ribeiro, and Y. Messaddeq

Citation: Journal of Applied Physics 95, 5451 (2004); doi: 10.1063/1.1704845

View online: $\mathrm{http}: / / \mathrm{dx}$.doi.org/10.1063/1.1704845

View Table of Contents: http://scitation.aip.org/content/aip/journal/jap/95/10?ver=pdfcov

Published by the AIP Publishing

\title{
Aplp $\operatorname{Re}$-register for Table of Content Alerts
}

\section{Create a profile.




\title{
Dynamics of $\mathrm{Tm}-\mathrm{Ho}$ energy transfer and deactivation of the ${ }^{3} \mathrm{~F}_{4}$ low level of thulium in fluorozirconate glasses
}

\author{
L. D. da Vila, L. Gomes, ${ }^{\text {a) }}$ and L. V. G. Tarelho \\ Centro de Lasers e Aplicações, IPEN-SP, Travessa R 400, Cidade Universitária, CEP 05508-900, \\ São Paulo, Brazil \\ S. J. L. Ribeiro and Y. Messaddeq \\ Laboratório de Materiais Fotônicos, Instituto de Química de Araraquara, UNESP, São Paulo, Brazil
}

(Received 18 August 2003; accepted 24 February 2004)

\begin{abstract}
The mechanism involved in the $\mathrm{Tm}^{3+}\left({ }^{3} \mathrm{~F}_{4}\right) \rightarrow \mathrm{Ho}^{3+}\left({ }^{5} \mathrm{I}_{7}\right)$ energy transfer and $\mathrm{Tm}^{3+}\left({ }^{3} \mathrm{H}_{4},{ }^{3} \mathrm{H}_{6}\right)$ $\rightarrow \mathrm{Tm}^{3+}\left({ }^{3} \mathrm{~F}_{4},{ }^{3} \mathrm{~F}_{4}\right)$ cross relaxation as a function of the donor and acceptor concentrations was investigated in Tm-Ho-codoped fluorozirconate glasses. The experimental transfer rates were determined for the $\mathrm{Tm} \rightarrow$ Ho energy transfer from the best fit of the acceptor luminescence decay using an expression which takes into account the Inokuti-Hirayama model and localized donor-to-acceptor interaction solution. The original acceptor solution derived from the InokutiHirayama model fits well the acceptor luminescence transient only for low-concentrated systems. The results showed that a fast excitation diffusion that occurs in a very short time $\left(t \ll \gamma^{-2}\right)$ reduces the mean distance between an excited donor $\left(D^{*}\right)$ and the acceptor $(A)$. A localized donor-to-acceptor interaction takes place, leading to an exponential decay of donors as an average of the microscopic rate equation solution of each $D^{*}-A$ pair separated by distance $R$ that contributes in addition to the Inokuti-Hirayama solution. The observation that the experimental transfer rates were always much bigger than the one predicted by the diffusion model, in which the energy transfer process is assisted by excitation migration among donors state, reinforces the existence of a fast excitation diffusion among donor ions before the energy transfer to acceptor already observed in $\mathrm{Yb}$ :Er:ZBLAN. The fast excitation diffusion effect was observed to dominate both the $\mathrm{Tm} \rightarrow \mathrm{Tm}$ cross relaxation and $\mathrm{Tm} \rightarrow$ Ho energy transfer ions from ${ }^{3} \mathrm{H}_{4}$ and ${ }^{3} \mathrm{~F}_{4}$ thulium states, respectively. (C) 2004 American Institute of Physics. [DOI: 10.1063/1.1704845]
\end{abstract}

\section{INTRODUCTION}

Rare-earth-doped fluoride glasses have been reported as a promising glass for optical applications because of their characteristics, such as low phonon energy and good capacity to accept lanthanide dopants. The low phonon energies of the fluoride glasses $\left(<600 \mathrm{~cm}^{-1}\right)$ allow the observation of rare-earth lasers emissions (about 30) (Refs. 1-3) in a large optical range. Particularly, laser emissions near 1.5 and 2.0 $\mu \mathrm{m}$ have important technological applications in telecommunications and medicine, respectively. In the telecommunications area, $\mathrm{Pr}^{3+}, \mathrm{Tm}^{3+}$ and $\mathrm{Er}^{3+}$, with respective laser emissions at $1.3,1.4$, and $1.55 \mu \mathrm{m}$, are candidates for amplification operations. ${ }^{4-6}$ These wavelengths are in the region where the silica glass, used to carry large volumes of information, has a minimal optical loss. Because of the low phonon energies of the fluoride glasses $\left(<600 \mathrm{~cm}^{-1}\right)$, the multiphonon relaxation of excited states of rare earths is strongly reduced, improving the efficiency of the rare-earth fluorescence and increasing the amplification gain. In the praseodymium-doped fiber amplifier (PDFA) and amplifiers based on thulium-doped fibers, amplification gains of $40 \mathrm{~dB}$ $\left(\mathrm{Pr}^{3+}\right)$ and $30 \mathrm{~dB}\left(\mathrm{Tm}^{3+}\right)$ have been obtained. ${ }^{1}$

Fluoride glasses can be melted over a wide range of compositions. In this work we used fluorozirconate glass

a)Electronic mail: lgomes@net.ipen.br
(ZBLAN) $\left(\mathrm{ZrF}_{4}-\mathrm{BaF}_{2}-\mathrm{LaF}_{3}-\mathrm{AlF}_{3}-\mathrm{NaF}\right)$ as matrix, $\mathrm{Tm}^{3+}$ as doping, and $\mathrm{Ho}^{3+}$ as codoping ions. The $\mathrm{Tm}^{3+}$ is a fourlevel laser which has important advantages for amplification purposes since the lower laser level ${ }^{3} \mathrm{~F}_{4}$ remains unpopulated. $\mathrm{Ho}^{3+}\left({ }^{5} \mathrm{I}_{7}\right)$ may play an important role in the "deactivation" of the ${ }^{3} \mathrm{~F}_{4}$ lower laser level of $\mathrm{Tm}^{3+}$. Tm:Ho:ZBLAN fluoride glass is also an attractive material for infrared laser fibers because of its efficient energy transfer $(\mathrm{ET}) \mathrm{Tm}^{3+}\left({ }^{3} \mathrm{~F}_{4}\right) \rightarrow \mathrm{Ho}^{3+}\left({ }^{5} \mathrm{I}_{7}\right)$, which is followed by important ${ }^{5} \mathrm{I}_{7} \rightarrow{ }^{5} \mathrm{I}_{8}$ laser emission of $\mathrm{Ho}^{3+}$ around $2 \mu \mathrm{m}$.

The present article reports on our studies of the mechanism involved in the $\mathrm{Tm}^{3+}\left({ }^{3} \mathrm{~F}_{4}\right) \rightarrow \mathrm{Ho}^{3+}\left({ }^{5} \mathrm{I}_{7}\right)$ ET and $\mathrm{Tm}^{3+}\left({ }^{3} \mathrm{H}_{4},{ }^{3} \mathrm{H}_{6}\right) \rightarrow \mathrm{Tm}^{3+}\left({ }^{3} \mathrm{~F}_{4},{ }^{3} \mathrm{~F}_{4}\right)$ cross-relaxation (CR) processes observed in Tm:Ho:ZBLAN glasses, using several combinations of $\mathrm{Tm}^{3+}$ and $\mathrm{Ho}^{3+}$ concentrations. In this sense, first, a microscopic analysis was performed considering the five possible ET processes, which occur for Tm:Ho:ZBLAN glasses: (i) $\mathrm{Tm}^{3+}\left({ }^{3} \mathrm{~F}_{4},{ }^{3} \mathrm{H}_{6}\right) \rightarrow \mathrm{Tm}^{3+}$ $\left({ }^{3} \mathrm{H}_{6},{ }^{3} \mathrm{~F}_{4}\right)$ migration, (ii) $\mathrm{Tm}^{3+}\left({ }^{3} \mathrm{~F}_{4}\right) \rightarrow \mathrm{Ho}^{3+}\left({ }^{5} \mathrm{I}_{7}\right)$ energy transfer, (iii) $\mathrm{Ho}^{3+}\left({ }^{5} \mathrm{I}_{7}\right) \rightarrow \mathrm{Tm}^{3+}\left({ }^{3} \mathrm{~F}_{4}\right)$ backtransfer, (iv) $\mathrm{Tm}^{3+}\left({ }^{3} \mathrm{H}_{4},{ }^{3} \mathrm{H}_{6}\right) \rightarrow \mathrm{Tm}^{3+}\left({ }^{3} \mathrm{~F}_{4},{ }^{3} \mathrm{~F}_{4}\right)$ cross relaxation, and (v) $\mathrm{Tm}^{3+}\left({ }^{3} \mathrm{H}_{4},{ }^{3} \mathrm{H}_{6}\right) \rightarrow \mathrm{Tm}^{3+}\left({ }^{3} \mathrm{H}_{6},{ }^{3} \mathrm{H}_{4}\right)$ migration. The donor-to-donor, donor-to-acceptor, and acceptor-to-donor energy transfer constants were determined and applied to estimate the expected transfer rates for the case of an energy transfer assisted by a diffusion model. The expected transfer 
rate values were compared to the experimental transfer rates obtained from a macroscopic analysis of the measured luminescence decay of the ${ }^{5} \mathrm{I}_{7}$ state of $\mathrm{Ho}^{3+}$ at $\sim 2 \mu \mathrm{m}$ and the ${ }^{3} \mathrm{H}_{4}$ state of $\mathrm{Tm}^{3+}$ at $\sim 1.5 \mu \mathrm{m}$. The experimental transfer rates and efficiencies were determined for $\mathrm{Tm} \rightarrow$ Ho energy transfer from the best fit of the luminescence decay curve using a theoretical expression derived for the acceptor luminescence decay based on the Inokuti-Hirayama ${ }^{7}$ approach. We have already shown that the Inokuti-Hirayama solution from the acceptor viewpoint is an important tool to investigate the mechanism of resonant energy transfer among tripleionized rare-earth ions in glasses. ${ }^{8}$ An expression in which the Inokuti-Hirayama approach is used together with the proposed localized donor-to-acceptor interaction [dipoledipole $(s=6)]$ solution has been used in the determination of experimental transfer rates and efficiencies for Tm-Ho, $\mathrm{Tm}-\mathrm{Tm}$ cross relaxation and $\mathrm{Tm}-\mathrm{Tm}$ migration. The temporal dynamics of the excited levels of $\mathrm{Tm}^{3+}$ and $\mathrm{Ho}^{3+}$ ions were measured using a pulsed laser excitation (4 ns) from a tunable optical parametric oscillator (OPO) pumped by the second harmonic of a $Q$-switched Nd-YAG laser which can pump exactly the level to be investigated. It is important to emphasize that the donor state ${ }^{3} \mathrm{~F}_{4}$ of $\mathrm{Tm}^{3+}$ ions was selectively excited at $1.67 \mu \mathrm{m}$ in the case of the $\mathrm{Tm} \rightarrow$ Ho energy transfer analysis (this excitation does not excite Ho ions). In this case, the $\mathrm{Ho}^{3+}$ luminescence transient was observed at 2 $\mu \mathrm{m}$ from where the most important information was derived. The Tm $\leftarrow$ Ho backtransfer cannot be experimentally observed when exciting Ho ions at $2 \mu \mathrm{m}$ and measuring the $\mathrm{Tm}^{3+}$ emission at $1.8 \mu \mathrm{m}$ because the net direction of the energy transfer points to the Ho direction $\left(C_{\mathrm{Tm} \rightarrow \mathrm{Ho}}\right.$ $=0.95 C_{\mathrm{Tm} \leftarrow \mathrm{Ho}}$ ). However, this mechanism exists and its microscopic parameter $C_{A D}$ can be calculated and compared with the direct transfer constant $C_{D A}$. As a consequence, an effective transfer parameter is given by $C_{D A}$ (net) $=C_{D A}$ $-C_{A D}$. In the case of $\mathrm{Tm} \rightarrow \mathrm{Tm}$ cross relaxation, the decay of $\mathrm{Tm}^{3+}$ luminescence at $1.47 \mu \mathrm{m}$ from the ${ }^{3} \mathrm{H}_{4}$ excited state was measured after selective laser excitation at $0.78 \mu \mathrm{m}$. This excitation excites only $\mathrm{Tm}^{3+}$ ions in Tm:Ho:ZBLAN and Tm:ZBLAN glasses. Excitation migration (or diffusion) through ${ }^{3} \mathrm{H}_{4}$ excited states of $\mathrm{Tm}^{3+}$ plays an important role in the $\mathrm{Tm} \rightarrow \mathrm{Tm}$ cross relaxation, but cannot be separately observed. The same argument is also applied to the case of excitation migration (or diffusion) through ${ }^{3} \mathrm{~F}_{4}$ excited states of thulium ions, which plays an important role in the Tm $\rightarrow$ Ho energy transfer.

\section{EXPERIMENT}

\section{A. Glass preparation}

Thulium and holmium fluorides were used, respectively, as codopant and dopant starting materials. They were prepared by fluorination of the respective ultrapure oxides (99.999\%) from Alfa Aesar. Other chemicals employed to prepare ZBLAN glasses were the grade reagents $(>99.9 \%)$ fluorides: $\mathrm{ZrF}_{4}$ (Fluortran), $\mathrm{BaF}_{2}$ (Alfa Aesar), $\mathrm{LaF}_{3}$ (reactron, Alfa Aesar), and $\mathrm{AlF}_{3}$ and $\mathrm{NaF}$ (Fluortran). Two series of Tm:Ho:ZBLAN glasses were prepared with the following compositions, where $x$ and $y$ are given in mol \%:
(i)
$(99-x)\left(53 \mathrm{ZrF}_{4} \cdot 20 \mathrm{BaF}_{2} \cdot 4 \mathrm{LaF}_{3} \cdot 3 \mathrm{AlF}_{3} \cdot 20 \mathrm{NaF}\right) \cdot x \mathrm{TmF}_{3} \cdot 1 \mathrm{HoF}_{3}$
$(x=0,0.5,1,3,6$, and 9),
(ii)
$(99-y)\left(53 \mathrm{ZrF}_{4} \cdot 20 \mathrm{BaF}_{2} \cdot 4 \mathrm{LaF}_{3} \cdot 3 \mathrm{AlF}_{3} \cdot 20 \mathrm{NaF}\right) \cdot 1 \mathrm{TmF}_{3} \cdot y \mathrm{HoF}_{3}$
$(y=0,0.5,2,3$, and 4$)$.

Tm:Ho:ZBLAN glasses of $5 \mathrm{~g}$ were produced by melting processing at $750-800^{\circ} \mathrm{C}$ for $2 \mathrm{~h}$ in a tubular furnace. A platinum crucible in form of tube was used as sample container. Annealing at $260{ }^{\circ} \mathrm{C}$ for $2 \mathrm{~h}$ was performed after casting. The rectangular samples were polished using isopropyl alcohol as lubricant agent.

\section{B. Spectroscopic measurements}

A time-resolved luminescence spectroscopy was employed to measure the acceptor $(A)$ luminescence transient induced by resonant laser excitation of the donor $(D)$ state. The luminescence and lifetimes of excited $\mathrm{Tm}^{3+}$ and $\mathrm{Ho}^{3+}$ were measured using a pulsed laser excitation (4 ns) from a tunable optical parametric oscillator pumped by the second harmonic of a $Q$-switched Nd-YAG laser from Quantel. Laser excitation at 0.78 and $1.67 \mu \mathrm{m}$ was used to excite the ${ }^{3} \mathrm{H}_{4}$ and ${ }^{3} \mathrm{~F}_{4}$ states of $\mathrm{Tm}^{3+}$, respectively. The luminescence signals, as well the time-dependent luminescence of the donor (or the activator), were detected by a InSb $(77 \mathrm{~K}$ ) infrared detector (Judson model J10D) with a fast preamplifier (re- sponse time of $0.5 \mu \mathrm{s})$ and analyzed using a signalprocessing boxcar (PAR 4402) (luminescence measurements) or a digital 200-MHz oscilloscope from Tektronix (TDS 410) (time-dependent luminescence measurements). Both fluorescence spectrum and decay times were measured at $300 \mathrm{~K}$.

\section{RESULTS}

\section{A. Determination of the energy transfer microparameters}

Schematic energy level diagrams showing some energy states of $\mathrm{Tm}^{3+}$ and $\mathrm{Ho}^{3+}$ ions with the respective $1.47 \mu \mathrm{m}$ $\left({ }^{3} \mathrm{H}_{4}\right)$ and $2 \mu \mathrm{m}\left({ }^{5} \mathrm{I}_{7}\right)$ emission transitions, as well as the possible energy transfer mechanisms for Tm:Ho:ZBLAN glasses, are presented in Figs. 1(a) and 1(b). The following notations were adopted for the energy transfer processes investigated:

(1) $\left({ }^{3} \mathrm{~F}_{4}\right) \mathrm{Tm} \rightarrow \mathrm{Tm}$ migration for $\mathrm{Tm}^{3+}\left({ }^{3} \mathrm{~F}_{4},{ }^{3} \mathrm{H}_{6}\right) \rightarrow \mathrm{Tm}^{3+}$ $\left({ }^{3} \mathrm{H}_{6},{ }^{3} \mathrm{~F}_{4}\right)$,

(2) $\mathrm{Tm} \rightarrow$ Ho ET for $\mathrm{Tm}^{3+}\left({ }^{3} \mathrm{~F}_{4}\right) \rightarrow \mathrm{Ho}^{3+}\left({ }^{5} \mathrm{I}_{7}\right)$, 


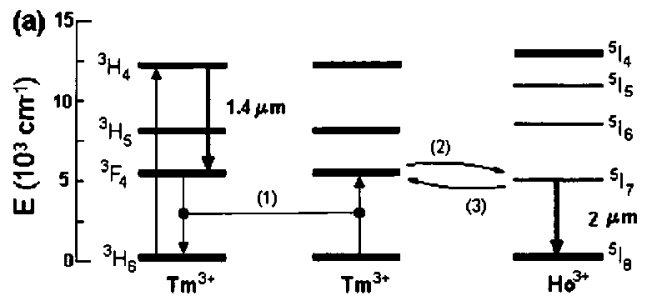

(b)

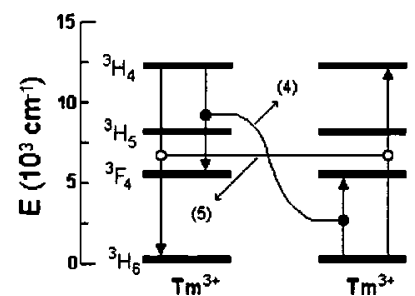

FIG. 1. Simplified energy level diagram of Tm:Ho:ZBLAN which exhibits five possible energy transfer processes as indicated. (a) exhibits the Tm-Ho transfers according to $(1)\left({ }^{3} \mathrm{~F}_{4}\right) \mathrm{Tm}-\mathrm{Tm}$ migration involving the ${ }^{3} \mathrm{~F}_{4}$ excited (donor) and ${ }^{3} \mathrm{H}_{6}$ ground (acceptor) states; (2) $\mathrm{Tm} \rightarrow$ Ho energy transfer where the ${ }^{3} \mathrm{~F}_{4}(\mathrm{Tm})$ state is the donor and the ${ }^{5} \mathrm{I}_{7}(\mathrm{Ho})$ state is the acceptor; (3) $\mathrm{Tm} \leftarrow$ Ho backtransfer (BT) (the intrinsic reverse transfer). (b) exhibits the $\mathrm{Tm}-\mathrm{Tm}$ transfers according to (4) $\mathrm{Tm}-\mathrm{Tm}$ cross relaxation being the ${ }^{3} \mathrm{H}_{4}$ the donor state and the ${ }^{3} \mathrm{H}_{6}$ ground state as the acceptor; (5) $\left({ }^{3} \mathrm{H}_{4}\right)$ Tm-Tm migration having the ${ }^{3} \mathrm{H}_{4}$ excited state as the donor and the ${ }^{3} \mathrm{H}_{6}$ ground state as the acceptor.

(3) $\mathrm{Ho} \rightarrow \mathrm{Tm}$ backtransfer (BT) for $\mathrm{Ho}^{3+}\left({ }^{5} \mathrm{I}_{7}\right) \rightarrow \mathrm{Tm}^{3+}$ $\left({ }^{3} \mathrm{~F}_{4}\right)$,

(4) $\mathrm{Tm} \rightarrow \mathrm{Tm}$ CR for $\mathrm{Tm}^{3+}\left({ }^{3} \mathrm{H}_{4},{ }^{3} \mathrm{H}_{6}\right) \rightarrow \mathrm{Tm}^{3+}\left({ }^{3} \mathrm{~F}_{4},{ }^{3} \mathrm{~F}_{4}\right)$, (5) $\left({ }^{3} \mathrm{H}_{4}\right) \quad \mathrm{Tm} \rightarrow \mathrm{Tm}$ migration for $\mathrm{Tm}^{3+}\left({ }^{3} \mathrm{H}_{4},{ }^{3} \mathrm{H}_{6}\right)$ $\rightarrow \mathrm{Tm}^{3+}\left({ }^{3} \mathrm{H}_{6},{ }^{3} \mathrm{H}_{4}\right)$.

In order to optimize the $\mathrm{Tm} \rightarrow$ Ho ET process, the concentration effect of each dopant ion must be investigated in detail. For example, the $\mathrm{Tm}^{3+}$ ion at high concentration allows efficient $\mathrm{Tm} \rightarrow \mathrm{Tm} \mathrm{CR}$ in which two $\mathrm{Tm}^{3+}$ ions are generated in the ${ }^{3} \mathrm{~F}_{4}$ excited state for each $\mathrm{Tm}^{3+}$ ion in the ${ }^{3} \mathrm{H}_{4}$ state [see mechanism 4 in Fig. 1(b)]. The energy is then transferred to the $\mathrm{Ho}^{3+}$ ions ( $\mathrm{Tm} \rightarrow \mathrm{Ho}$ ET), which exhibit luminescence near $2 \mu \mathrm{m}$ suitable for technological applications. Another nonradiative energy transfer mechanism possible to the Tm:Ho:ZBLAN system is the $\left({ }^{3} \mathrm{H}_{4}\right) \mathrm{Tm} \rightarrow \mathrm{Tm}$ migration [see mechanism 5 in Fig. 1(b)].

Figures 2(a) and 2(b) show the fluorescence spectra for the Tm- and Tm:Ho-doped ZBLAN. Emissions around 1.5 and $1.8 \mu \mathrm{m}$ are observed for Tm:ZBLAN [Fig. 2(a)] and Tm:Ho:ZBLAN samples [Fig. 2(b)]. These are attributed to ${ }^{3} \mathrm{H}_{4} \rightarrow{ }^{3} \mathrm{~F}_{4}$ and ${ }^{3} \mathrm{~F}_{4} \rightarrow{ }^{3} \mathrm{H}_{6}$ emissions of $\mathrm{Tm}^{3+}$, respectively. Since the $\mathrm{Tm}-\mathrm{Ho}$ energy transfer partially depopulates the ${ }^{3} \mathrm{~F}_{4}$ excited state of $\mathrm{Tm}^{3+}$, a weak residual $\mathrm{Tm}^{3+}$ $\left({ }^{3} \mathrm{~F}_{4}\right)$ luminescence at $\sim 1.8 \mu \mathrm{m}(\sim 20 \%)$ is observed in Tm:Ho:ZBLAN. This effect is explained based on the Tm $\leftarrow$ Ho backtransfer process. In addition, a strong emission at $\sim 2 \mu \mathrm{m}$ due to the ${ }^{5} \mathrm{I}_{7} \rightarrow{ }^{5} \mathrm{I}_{8}$ fluorescence of $\mathrm{Ho}^{3+}$ ions is observed in Fig. 2(b). The lifetime of ${ }^{3} \mathrm{H}_{4},{ }^{3} \mathrm{~F}_{4}$ excited states of $\mathrm{Tm}^{3+}$ and ${ }^{5} \mathrm{I}_{7}$ of $\mathrm{Ho}^{3+}$ ions have been measured for single-doped ZBLAN glasses. Figures 3(a)-3(c) show the luminescence decays and best fits. A nonexponential decay with a lifetime of $1.5 \mathrm{~ms}$ has been measured for ${ }^{3} \mathrm{H}_{4}\left(\mathrm{Tm}^{3+}\right)$ emission at $1.47 \mu \mathrm{m}$ in $\mathrm{Tm}(0.5 \mathrm{~mol} \%)$ :ZBLAN. In this case

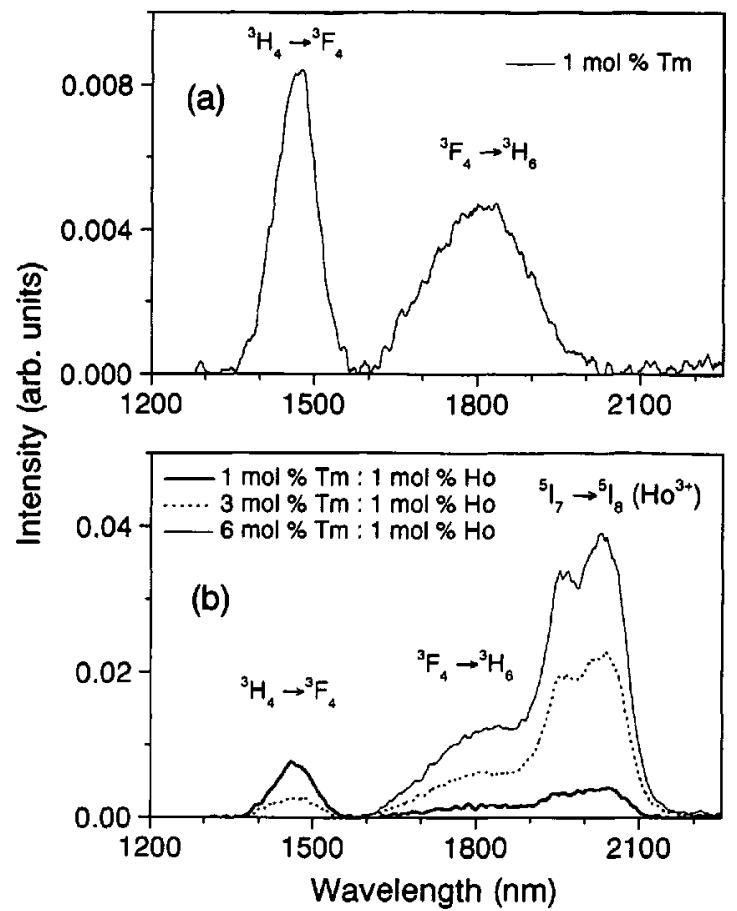

FIG. 2. Infrared luminescence spectrum of $\mathrm{Tm}^{3+}$ and $\mathrm{Ho}^{3+}$ in ZBLAN glass. (a) shows the spectrum of $\mathrm{Tm}(1 \%)$ single-doped ZBLAN and (b) shows the spectrum of $\operatorname{Tm}(x \%): \operatorname{Ho}(1 \%)$ :ZBLAN after laser excitation at $0.79 \mu \mathrm{m}$ with $12 \mathrm{~mJ}$ at $300 \mathrm{~K}$.

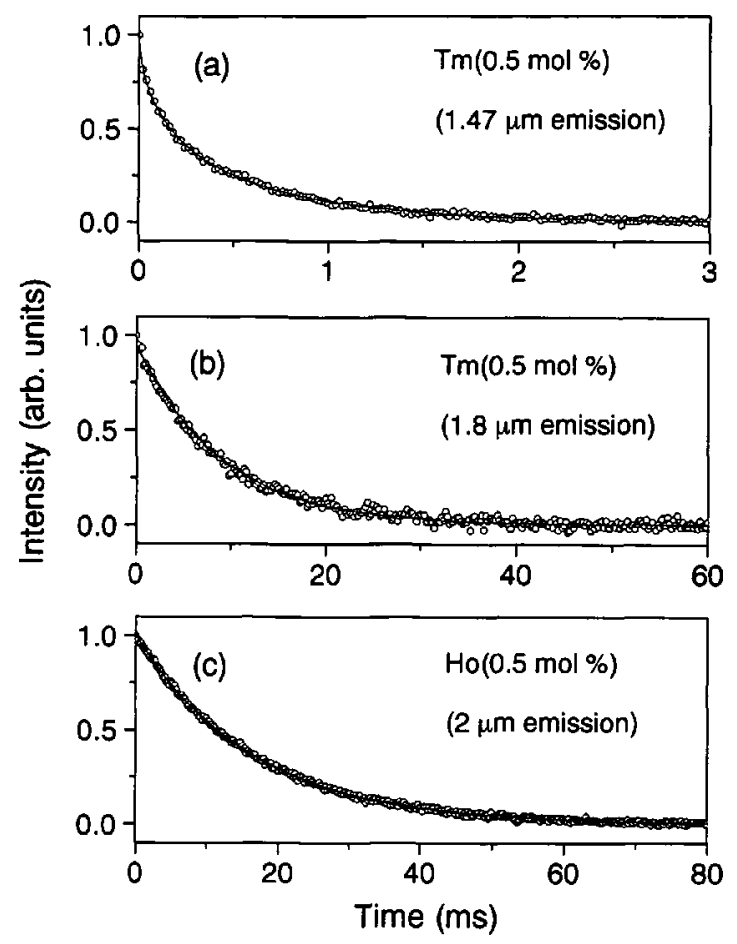

FIG. 3. (a) shows the fluorescence decay of $\mathrm{Tm}^{3+}$ ions at $1.47 \mu \mathrm{m}$ after laser excitation at $0.78 \mu \mathrm{m}(12 \mathrm{~mJ}, 4 \mathrm{~ns})$ measured in $\operatorname{Tm}(0.5$ mol \%):ZBLAN at $300 \mathrm{~K}$ (open circles). The solid line represents the Inokuti-Hirayama best fit $\left(\gamma=12.1 \mathrm{~s}^{-1 / 2}\right)$. (b) shows the fluorescence decay of the ${ }^{3} \mathrm{~F}_{4}$ state at $1.8 \mu \mathrm{m}$ after laser excitation at $1.671 \mu \mathrm{m}$ (open circles). The solid line is the exponential fitting $(\tau=8.9 \mathrm{~ms})$. (c) shows the fluorescence decay of the ${ }^{5} \mathrm{I}_{7}$ state at $2 \mu \mathrm{m}$ after laser excitation at $1.95 \mu \mathrm{m}$ (open circles). The solid line is the exponential fitting $(\tau=16.4 \mathrm{~ms})$. 
a good Inokuti-Hirayama fit was obtained [see solid line of Fig. 3(a)]. The luminescence decay of the ${ }^{3} \mathrm{~F}_{4}$ state at $1.8 \mu \mathrm{m}$ is exponential with a lifetime of $8.9 \mathrm{~ms}$ in $\operatorname{Tm}(0.5$ mol \%):ZBLAN [see Fig. 3(b)]. The decay of the ${ }^{5} \mathrm{I}_{7}$ state at $2 \mu \mathrm{m}$ is exponential with a time constant of $16.4 \mathrm{~ms}$ observed in $\mathrm{Ho}(0.5 \mathrm{~mol} \%)$ :ZBLAN [see Fig. 3(c)].

Donor-donor $(D D)$, donor-acceptor $(D A)$, and acceptor-donor $(A D)$ energy transfer constants $\left(C_{D D}, C_{D A}, C_{A D}\right)$, critical radii $\left(R_{D D}, R_{D A}\right)$, and critical concentrations $\left(c_{0}\right)$ were calculated for (i) $\left({ }^{3} \mathrm{~F}_{4}\right) \mathrm{Tm} \rightarrow \mathrm{Tm}$ migration (mechanism 1), (ii) $\mathrm{Tm} \rightarrow$ Ho ET (mechanism 2), (iii) $\mathrm{Ho} \rightarrow \mathrm{Tm} \mathrm{BT}$ (mechanism 3), (iv) $\mathrm{Tm} \rightarrow \mathrm{Tm} \mathrm{CR}$ (mechanism 4), and (v) $\left({ }^{3} \mathrm{H}_{4}\right) \mathrm{Tm} \rightarrow \mathrm{Tm}$ migration (mechanism 5). The following expressions were used for energy transfer constant determination:

$$
\begin{aligned}
& C_{D D}=\frac{R_{D D}^{6}}{\tau_{D}} \quad[(\mathrm{i}) \text { and }(\mathrm{v}) \text { processes }], \\
& C_{D A}=\frac{R_{D A}^{6}}{\tau_{D}} \quad[(\text { ii) } \text { and (iv) processes }], \\
& C_{A D}=\frac{R_{A D}^{6}}{\tau_{A}} \quad[(\text { iii) } \text { process }],
\end{aligned}
$$

where $\tau_{D}$ and $\tau_{A}$ is the total lifetime of the donor (Tm) and acceptor (Ho) states, respectively, measured for single-doped samples. The critical radii $R_{D D}, R_{D A}$, and $R_{A D}$ were calculated using the extended overlap integral method ${ }^{9}$ since the $D D, D A$, and $A D$ energy transfer processes for the Tm:Ho system are nonresonant (or phonon assisted). In this method a nonvanishing overlap integral is produced from a translation of the donor emission spectrum towards the acceptor absorption. The expressions for direct transfer $(D A)$ and backtransfer $(A D)$ are

$$
\begin{aligned}
R_{D A}^{6}= & \frac{6 c \tau_{D}}{(2 \pi)^{4} n^{2}} \frac{g_{D}^{\text {low }}}{g_{D}^{\text {up }}} \sum_{n=0}^{\infty} \int \sigma_{\text {emis }}^{D}\left(\lambda_{N}^{+}\right) \sigma_{\text {abs }}^{A}(\lambda) d \lambda \\
& \times\left(\sum_{j=0}^{N} P_{(N-j)}^{+} P_{j}^{-} P_{j}^{+}\right)
\end{aligned}
$$

$($ for $\mathrm{Tm} \rightarrow \mathrm{Ho} \mathrm{ET})$,

$$
\begin{aligned}
R_{D D(\text { or } A D)}^{6}= & \frac{6 c \tau_{A}}{(2 \pi)^{4} n^{2}} \frac{g_{A}^{\text {low }}}{g_{A}^{\text {up }}} \sum_{n=0}^{\infty} \int \sigma_{\text {emis }}^{D(\text { or } A)} \\
& \times\left(\lambda_{N}^{-}\right) \sigma_{\text {abs }}^{D}(\lambda) d \lambda\left(\sum_{j=0}^{N} P_{(N-j)}^{-} P_{j}^{+} P_{j}^{-}\right)
\end{aligned}
$$

[for $\mathrm{Tm} \rightarrow \mathrm{Tm} \mathrm{Cr},\left({ }^{3} \mathrm{H}_{4}\right) \mathrm{Tm} \rightarrow \mathrm{Tm},\left({ }^{3} \mathrm{~F}_{4}\right) \mathrm{Tm} \rightarrow \mathrm{Tm}$ migration (or Tm $\leftarrow$ Ho BT)], where $c$ is the light speed, $n$ the refractive index of the medium (1.5), $g_{\text {low }}^{D} / g_{\text {low }}^{A}$ and $g_{\text {up }}^{D} / g_{\text {up }}^{A}$ are the degeneracy of the respective lower and upper levels of the donor/acceptor, $N$ is the total number of phonons involved in the energy transfer process, $(N-j)$ is the number of phonons emitted (or created) by $D$ in the $D A$ and $D D$ transference ( $A$ in $A D$ backtransfer), and $j$ is the number of phonons absorbed (or annihilated) by $A$ ( $D$ in both $D D$ transference and $A D$ backtransfer). $\lambda_{N}^{+}$and $\lambda_{N}^{-}$denote the wavelengths translations of the emission cross-section spectra by

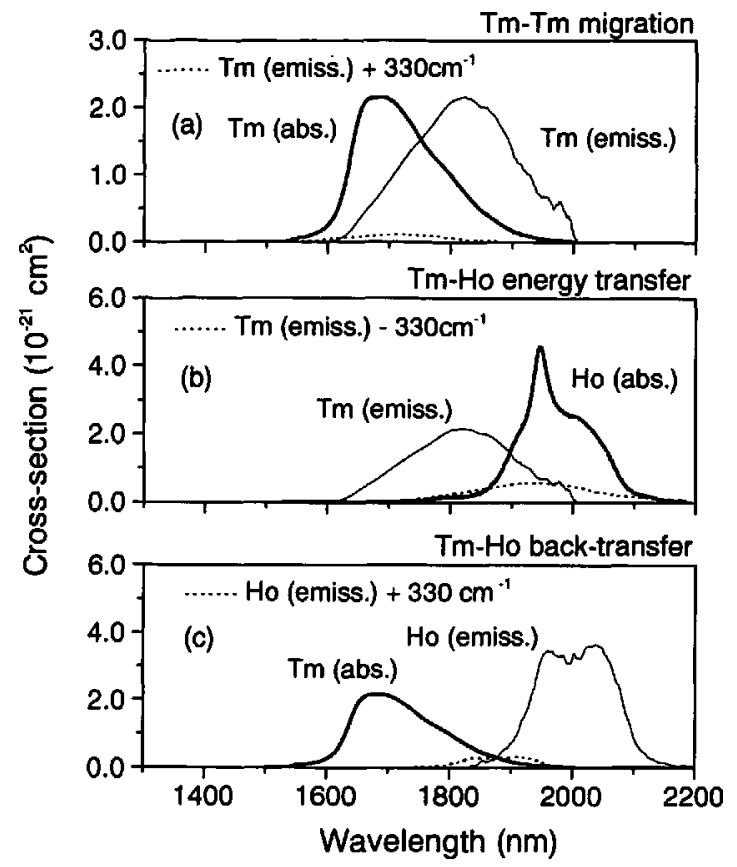

FIG. 4. (a) shows the spectral cross-section superposition between Tm $\left({ }^{3} \mathrm{H}_{6} \rightarrow{ }^{3} \mathrm{~F}_{4}\right)$ absorption and $\mathrm{Tm}\left({ }^{3} \mathrm{~F}_{4} \rightarrow{ }^{3} \mathrm{H}_{6}\right)$ emission involved in the $\left({ }^{3} \mathrm{~F}_{4}\right)$ $\mathrm{Tm}-\mathrm{Tm}$ migration. The dotted line of (a) exhibits the $\mathrm{Tm}^{3+}$ emission involving one-phonon absorption (or annihilation). (b) shows the superposition between the Tm $\left({ }^{3} \mathrm{~F}_{4} \rightarrow{ }^{3} \mathrm{H}_{6}\right)$ emission and the Ho $\left({ }^{5} \mathrm{I}_{8} \rightarrow{ }^{5} \mathrm{I}_{7}\right)$ absorption in the Tm $\rightarrow$ Ho ET. The dotted line of (b) shows the spectral overlap with $\mathrm{Tm}^{3+}$ emission involving one-phonon emission (or creation). (c) shows the overlap between the Ho $\left({ }^{5} \mathrm{I}_{7} \rightarrow{ }^{5} \mathrm{I}_{8}\right)$ emission and the Tm $\left({ }^{3} \mathrm{H}_{6} \rightarrow{ }^{3} \mathrm{~F}_{4}\right)$ ab-

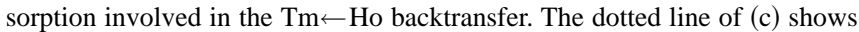
the overlap contribution with the $\mathrm{Ho}^{3+}$ emission involving one-phonon absorption (or annihilation).

$E=[N \hbar \omega]^{-1} \cdot \lambda_{N}^{+}$denotes the translations due to multiphonon emission by $D$ in the $D A$ transference. $\lambda_{N}^{-}$denotes the translations due to multiphonon absorption by $D$ in the $D D$ transference ( $A$ and $A D$ backtransfer). $P_{N-j}^{+}$is the probability of multiphonon emission by $D$, while $P_{N-j}^{-}$is the probability of multiphonon absorption by $D$ in the $D-D$ transference ( $A$ in $A D$ backtransfer). The electron-phonon coupling constant $S_{0}$ has been estimated to be $\sim 0.31$, and the mean phonon energy that couples with the phonon sideband is $\hbar \omega \sim 330 \mathrm{~cm}^{-1}$ in ZBLAN glasses. ${ }^{10}$ The critical concentration was calculated using

$$
c_{0}=\left(\frac{4 \pi}{3} R_{C}^{3}\right)^{-1},
$$

where $R_{C}$ is the critical radius of interaction.

Figures 4(a), 4(b) and 5(a), 5(b) show the spectral superposition between the emission and absorption cross-section spectra for the phonon-dependent energy transfer mechanisms in Tm:Ho:ZBLAN glasses. The strong spectral superposition observed [Figs. 4(a) and 4(b)] predicts an efficient ET for Tm:Ho:ZBLAN. A stronger overlap between emission and absorption cross sections for the $\left({ }^{3} \mathrm{H}_{4}\right) \mathrm{Tm} \rightarrow \mathrm{Tm}$ migration process in relation to the overlap verified for $\mathrm{Tm}$ $\rightarrow \mathrm{Tm}$ CR (cross-relaxation mechanism) has been obtained and can be observed in Figs. 5(a) and 5(b). These results indicate also that the donor-donor migration among ${ }^{3} \mathrm{H}_{4}$ thu- 


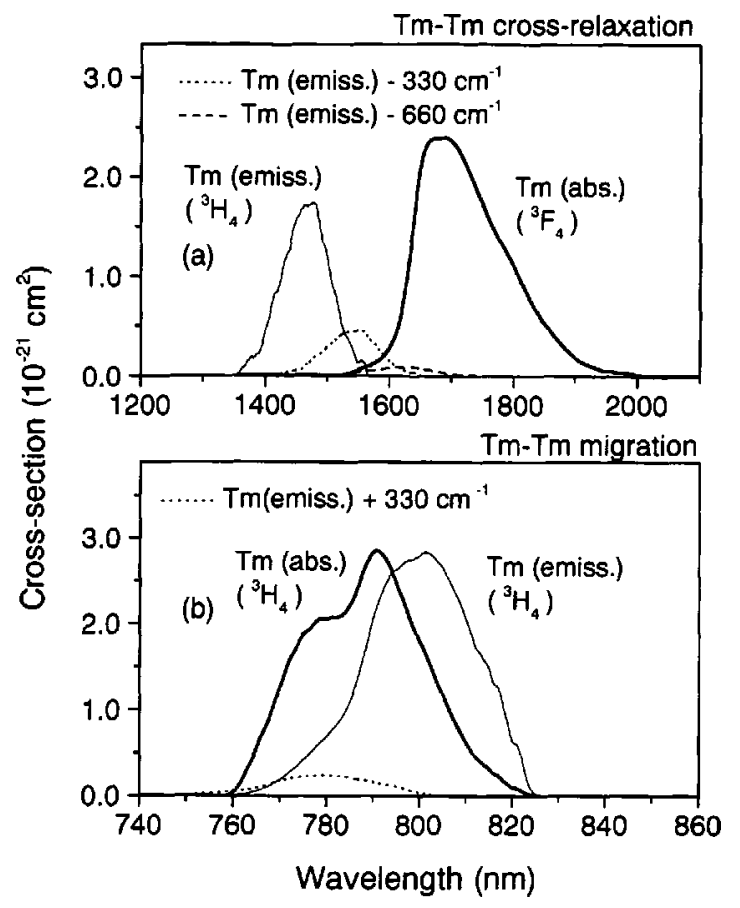

FIG. 5. (a) shows the spectral cross-section overlap between the Tm $\left({ }^{3} \mathrm{H}_{4}\right.$ $\left.\rightarrow{ }^{3} \mathrm{~F}_{4}\right)$ emission and $\mathrm{Tm}\left({ }^{3} \mathrm{H}_{6} \rightarrow{ }^{3} \mathrm{~F}_{4}\right)$ absorption involved in the Tm-Tm cross relaxation. The dashed lines of (a) exhibit the overlap contribution of the $\operatorname{Tm}\left({ }^{3} \mathrm{H}_{4}\right)$ emission involving one-phonon (dotted line) and two-phonon emission (dashed line). (b) shows the overlap between the $\mathrm{Tm}\left({ }^{3} \mathrm{H}_{6}\right.$ $\left.\rightarrow{ }^{3} \mathrm{H}_{4}\right)$ absorption and the $\operatorname{Tm}\left({ }^{3} \mathrm{H}_{4} \rightarrow{ }^{3} \mathrm{H}_{6}\right)$ emission near $0.80 \mu \mathrm{m}$ involved in the $\left({ }^{3} \mathrm{H}_{4}\right) \mathrm{Tm}-\mathrm{Tm}$ migration (solid lines). The dotted line in (b) represents the Tm emission involving one-phonon absorption (or annihilation process).

lium states is more important than the donor-donor migration among ${ }^{3} \mathrm{~F}_{4}$ states when higher excited levels of thulium ions are involved in the energy transfer in Tm:Ho:ZBLAN glasses.

Table I shows the phonons numbers and contribution term $(\%)$ to the total probability rate involved in the energy transfer. The microscopic parameters values for the nonradiative energy transfer for $\mathrm{Tm} \rightarrow \mathrm{Ho} \mathrm{ET}, \mathrm{Tm} \leftarrow \mathrm{Ho} \mathrm{BT},\left({ }^{3} \mathrm{~F}_{4}\right)$ $\mathrm{Tm} \rightarrow \mathrm{Tm}$ migration, $\mathrm{Tm} \rightarrow \mathrm{Tm} \mathrm{CR}$ and $\left({ }^{3} \mathrm{H}_{4}\right) \mathrm{Tm} \rightarrow \mathrm{Tm}$ migration are also presented in Table I. Comparing the several $\mathrm{N}$-phonon contribution terms (\%) one verifies that the transference $\left({ }^{3} \mathrm{~F}_{4}\right) \mathrm{Tm} \rightarrow \mathrm{Tm}$ and $\left({ }^{3} \mathrm{H}_{4}\right) \mathrm{Tm} \rightarrow \mathrm{Tm}$ migrations are not phonon dependent in these quasiresonant processes. The $\mathrm{Tm} \rightarrow \mathrm{Tm}$ CR transference is a multiphonon mechanism dominated by two-phonon creation $(59 \%)$. The $\mathrm{Tm} \rightarrow \mathrm{Ho}$ ET and $\mathrm{Ho} \rightarrow \mathrm{Tm}$ BT exhibit a competition between zero- and one-phonon processes. From $C_{D D}$ and $C_{D A}$ results it can be seen that the $\left({ }^{3} \mathrm{~F}_{4}\right) \mathrm{Tm} \rightarrow \mathrm{Tm}$ migration competes with the $\mathrm{Tm} \rightarrow$ Ho ET $\left(C_{D D} \sim 0.8 C_{D A}\right)$. A similar behavior in which $D \rightarrow D$ migration competes with the direct $D \rightarrow A$ energy transfer had been observed in other rare-earth-codoped fluoride systems, such as Yb:Er:ZBLAN glasses $^{8}$ and Tm:Ho:YLF ${ }^{9}$ crystals. A great difference between $C_{D D}$ and $C_{D A}$ values for $\mathrm{Tm} \rightarrow \mathrm{Tm} C \mathrm{CR}$ and $\left({ }^{3} \mathrm{H}_{4}\right) \mathrm{Tm} \rightarrow \mathrm{Tm}$ migrations has been observed in the present work $\left(C_{D D}\right.$ $\left.\sim 11 C_{D A}\right)$. This is an obvious result since the $\left({ }^{3} \mathrm{H}_{4}\right) \mathrm{Tm}$ $\rightarrow \mathrm{Tm}$ migration is a quasiresonant process, while $\mathrm{Tm}$ $\rightarrow \mathrm{Tm}$ CR is dominated by a two-phonon creation mechanism. A $C_{A D} / C_{D A}$ ratio estimated for the $\mathrm{Tm} \rightarrow$ Ho transfer was found to be 0.05 , which indicates that only $5 \%$ of the excited $\mathrm{Tm}^{3+}$ ions remain in the ${ }^{3} \mathrm{~F}_{4}$ state due to the existence of $\mathrm{Ho} \rightarrow \mathrm{Tm}$ backtransfer ( $A D$ process). However, we observed a thulium residual luminescence from ${ }^{3} \mathrm{~F}_{4}$ state of 25\% in Tm:Ho-doped ZBLAN glasses exhibiting a lifetime of $\sim 8.9 \mathrm{~ms}$, similar to the one found in Tm single-doped ZBLAN

\section{B. Analysis of the acceptor and donor luminescence transients}

The time evolution of ${ }^{5} \mathrm{I}_{7}\left(\mathrm{Ho}^{3+}\right)$ luminescence at $\sim 2$ $\mu \mathrm{m}$ and ${ }^{3} \mathrm{H}_{4}\left(\mathrm{Tm}^{3+}\right)$ at $\sim 1.5 \mu \mathrm{m}$ has been measured and analyzed for two sets of Tm:Ho:ZBLAN glasses:

(i) $(99-x)(\mathrm{ZBLAN}) \cdot x \mathrm{TmF}_{3} \cdot 1 \mathrm{HoF}_{3} \quad(x=0.5,1,3,6$, and $9 \mathrm{~mol} \%)$,

(ii) $(99-y)(\mathrm{ZBLAN}) \cdot 1 \mathrm{TmF}_{3} \cdot y \mathrm{HoF}_{3} \quad(y=0.5,2,3$, and 4 mol \%).

Analysis of the ${ }^{5} \mathrm{I}_{7}\left(\mathrm{Ho}^{3+}\right)$ luminescence transient is important for understanding the energy transfer involved in Tm-Ho ET, while the analysis of the ${ }^{3} \mathrm{H}_{4}\left(\mathrm{Tm}^{3+}\right)$ luminescence decay is important to determine the role of the $\mathrm{Tm}-\mathrm{Tm}$ migration in the $\mathrm{Tm}-\mathrm{Tm}$ cross-relaxation process.

Figures 6-9 exhibit the luminescent decay curves for the samples of sets (i) and (ii) used, respectively. Figures 6(a)6(c) and 7(a)-7(c) show the $\mathrm{Ho}^{3+}$ luminescence decay curves, and Figs. $8(\mathrm{a})-8(\mathrm{c})$ and $9(\mathrm{a})-9(\mathrm{c})$ show the $\mathrm{Tm}^{3+}$

TABLE I. Calculated microscopic parameters of the energy transfer processes observed in Tm:Ho:ZBLAN glass considering a dipole-dipole electric interaction $(s=6)$.

\begin{tabular}{lcccc}
\hline \hline Energy transfer & $\begin{array}{c}N \text { (No. of phonons) } \\
(\% \text { phonons })\end{array}$ & $\begin{array}{c}\text { Transfer constant } \\
\left(\mathrm{cm}^{6} \mathrm{~s}^{-1}\right)\end{array}$ & $R_{c}(\AA)$ & $c_{0}(\mathrm{~mol} \%)$ \\
\hline $\mathrm{Tm} \rightarrow \mathrm{Tm}$ (migration) & 0,1 & $C_{D D}=(3.27) \times 10^{-39}$ & 17.5 & 0.24 \\
$\left({ }^{3} \mathrm{~F}_{4},{ }^{3} \mathrm{H}_{6}\right) \rightarrow\left({ }^{3} \mathrm{~F}_{4},{ }^{3} \mathrm{H}_{6}\right)$ & $(93,7)$ & $C_{D A}=(4.29) \times 10^{-39}$ & 18.4 & 0.21 \\
$\mathrm{Tm} \rightarrow \mathrm{Ho}$ (energy transfer) & $0,1,2$ & & \\
$\left({ }^{3} \mathrm{~F}_{4} \rightarrow{ }^{5} \mathrm{I}_{7}\right)$ & $(53,40,7)$ & $C_{A D}=(0.21) \times 10^{-39}$ & 11.5 & 0.85 \\
$\mathrm{Ho} \rightarrow \mathrm{Tm}$ (backtransfer) & $0,1,2$ & & 3.0 \\
$\left({ }^{5} \mathrm{I}_{7} \rightarrow{ }^{3} \mathrm{~F}_{4}\right)$ & $(49,44,7)$ & $C_{D A}=(7.83) \times 10^{-41}$ & 7.0 & 3.85 \\
$\mathrm{Tm} \rightarrow \mathrm{Tm}$ (cross relaxation) & $0,1,2,3,4$ & & 1.14 \\
$\left({ }^{3} \mathrm{H}_{4},{ }^{3} \mathrm{H}_{6}\right) \rightarrow\left({ }^{3} \mathrm{H}_{4},{ }^{3} \mathrm{~F}_{4}\right)$ & $(1,23,59,16,1)$ & $C_{D D}=(88.96) \times 10^{-41}$ & 10.5 & \\
$\mathrm{Tm} \rightarrow \mathrm{Tm}($ migration) & 0,1 & & \\
$\left({ }^{3} \mathrm{H}_{4},{ }^{3} \mathrm{H}_{6}\right) \rightarrow\left({ }^{3} \mathrm{H}_{6},{ }^{3} \mathrm{H}_{4}\right)$ & $(92,8)$ & & \\
\hline \hline
\end{tabular}




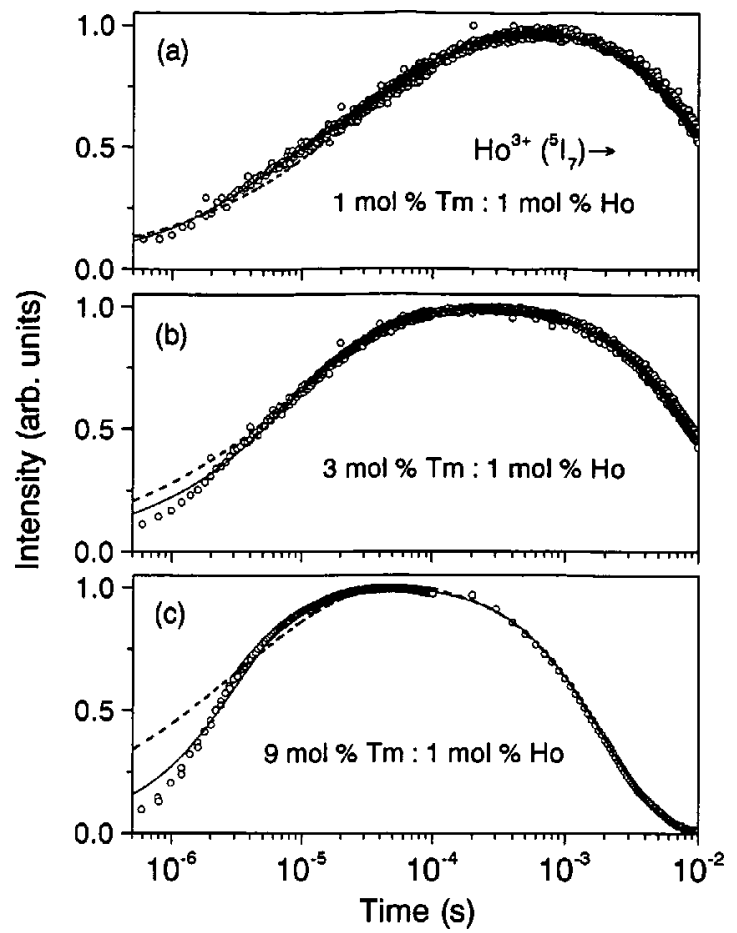

FIG. 6. Fluorescence of $\mathrm{Ho}^{3+}\left({ }^{5} \mathrm{I}_{7}\right)$ at $2 \mu \mathrm{m}$ induced by the $\mathrm{Tm} \rightarrow$ Ho ET by laser excitation of Tm ions at $1.67 \mu \mathrm{m}(10 \mathrm{~mJ}, 4 \mathrm{~ns}, 10 \mathrm{~Hz})$ measured for three $\operatorname{Tm}(x): \operatorname{Ho}(1 \%)$ :ZBLAN samples where $x=1 \mathrm{~mol} \%$ (a), $x$ $=3 \mathrm{~mol} \%$ (b), and $x=9 \mathrm{~mol} \%$ (c). The dashed lines represents the best fit using the Inokuti-Hirayama solution for the acceptor luminescence transient $\left(\mathrm{Ho}^{3+}\right)$ and the solid line represents the best fit using a solution that also includes the (acceptor) localized $D^{*}-A$ interaction contribution [Eq. (12) obtained for the proposed model].

luminescence decay curves. We observed a nonexponential rise time of $\mathrm{Ho}^{3+}$ luminescence at $2 \mu \mathrm{m}$ due to the Tm-Ho ET, followed by an exponential decay in Tm:Ho:ZBLAN. Also, a nonexponential decay was observed for $\mathrm{Tm}^{3+}\left({ }^{3} \mathrm{H}_{4}\right)$ luminescence at $1.47 \mu \mathrm{m}$ in both Tm $(0.5 \%)$ :ZBLAN and $\operatorname{Tm}(x \%): \operatorname{Ho}(y \%)$ :ZBLAN glasses.

The $\mathrm{Ho}^{3+}$ and $\mathrm{Tm}^{3+}$ luminescence transients were analyzed using the donor solution obtained by InokutiHirayama [for a dipole-dipole interaction $(s=6)$ ] (Ref. 7) and the acceptor solution based on the Inokuti-Hirayama model: ${ }^{8}$

$$
\begin{aligned}
& \bar{I}_{D}(t)=\exp \left(-\gamma \sqrt{t}-\frac{t}{\tau_{D}}\right) \quad \text { (for the donor decay), } \\
& \bar{I}_{A}(t)=\exp \left(-\frac{t}{\tau_{A}}\right)-\exp \left(-\gamma \sqrt{t}-\frac{t}{\tau_{D}}\right)
\end{aligned}
$$

(for the acceptor transient),

where $\gamma\left(\mathrm{s}^{-1 / 2}\right)$ is the energy transfer constant, $\tau_{D}$ is the intrinsic total lifetime of an isolated donor (Tm), and $\tau_{A}$ is the intrinsic lifetime of the acceptor (Ho). However, one can see that these solutions do not fit well the 2- $\mu \mathrm{m}$ Ho emission transient (or the 1.47- $\mu \mathrm{m}$ Tm emission) in the Tm:Ho system with an increase of Tm (or Ho concentration). It is observed also that the values of the $\gamma$ parameter are much larger than the theoretical values expected for each case of

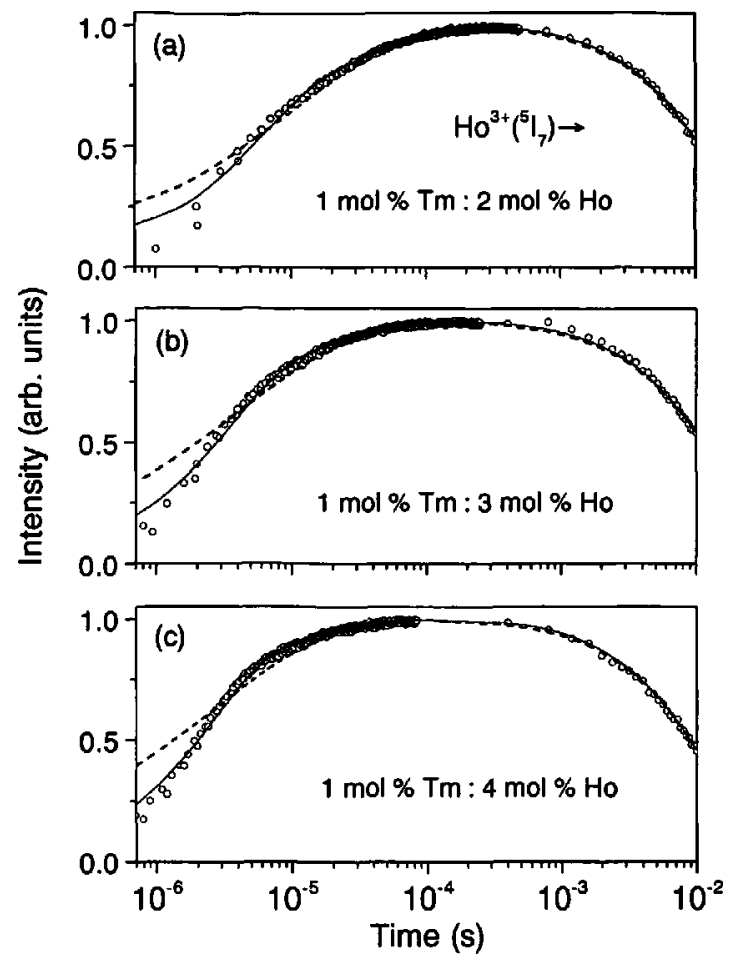

FIG. 7. Fluorescence decay of $\mathrm{Ho}^{3+}\left({ }^{5} \mathrm{I}_{7}\right)$ at $2 \mu \mathrm{m}$ excited with laser pulse at $1.67 \mu \mathrm{m}(10 \mathrm{~mJ})$ measured for three $\operatorname{Tm}(1 \%): \mathrm{Ho}(y)$ :ZBLAN where $y$ $=2 \mathrm{~mol} \%$ (a), $y=3 \mathrm{~mol} \%$ (b), and $y=4 \mathrm{~mol} \%$ (c). The dashed lines were obtained from the best fit using the Inokuti-Hirayama solution for the acceptor $\left(\mathrm{Ho}^{3+}\right)$ ion and solid lines represent the best fit using a solution that also includes the (acceptor) localized $D^{*}-A$ interaction contribution [according to Eq. (12)].

$\operatorname{Tm}(x): \operatorname{Ho}(y)$ :ZBLAN. As has been reported before, there is a fast excitation migration among donors that happens in a very short time $\left(t \ll \gamma^{2}\right)$ that modifies the excitation distribution between donors such that an excited donor ion $(\mathrm{Tm})$ feels an apparent increase of the acceptor concentration $\left(c_{A}\right.$ $\left.\rightarrow c_{A}^{\prime}\right)$. Let us now assume that after this fast diffusion there are two types of $D \rightarrow A$ interaction that are dependent on the distance $(R)$ involved in the $D^{*}-A$ pair:

(i) If $R>R_{C}$, the $D^{*} \rightarrow A$ energy transfer occurs as described in the Inokuti-Hirayama model: i.e., the excited donor interacts with all the acceptors present in the interaction volume in the limit of $V \rightarrow \infty$.

(ii) If $R<R_{C}$, a localized $D^{*} \rightarrow A$ energy transfer takes over and the average time solution will be given by $\bar{\phi}_{D}(t)$.

Considering that the decay solution for a $D^{*}-A$ pair is given by

$$
\phi_{D}(t, R)=\exp \left(-t / \tau_{D}\right) \exp \left[-t W_{D A}(R)\right],
$$

where the transfer rate is given by $W_{D A}(R)=C_{D A} / R^{6}$ and the normalized distribution function $f(R) d R$, which gives the fraction of $D^{*}-A$ pairs as a function of the separation distance $R$,

$$
f(R) d R=4 \pi R^{2} x_{A}^{\prime}\left(1-x_{A}^{\prime}\right)^{(4 \pi / 3) R^{3} c_{A}^{\prime}} d R,
$$

where $c_{A}^{\prime}$ is the apparent acceptor concentration and $x_{A}^{\prime}$ is the correspondent mol fraction, we have 


$$
\begin{aligned}
\bar{\phi}_{D}(t) & =\int \phi_{D}(t) f(R) d R=\exp \left(-t / \tau_{D}\right) \int \exp \left(-t C_{D A} / R^{6}\right) f(R) d R=\exp \left(-t / \tau_{D}\right) \int f(R) \sum_{n=0}^{\infty}\left(t C_{D A} / R^{6}\right)^{n} \frac{1}{n !} d R \\
& =\exp \left(-t / \tau_{D}\right)\left[1-t C_{D A}\left\langle R^{-6}\right\rangle+\left(t C_{D A}\right)^{2}\left\langle R^{-12}\right\rangle \frac{1}{2 !}-\cdots\right] \cong \exp \left(-t / \tau_{D}\right)\left[1-t C_{D A}\left\langle R^{-6}\right\rangle+\left(t C_{D A}\right)^{2}\left\langle R^{-6}\right\rangle^{2} \frac{1}{2 !}-\cdots\right] \\
& =\exp \left(-t / \tau_{D}\right) \exp \left(-t C_{D A}\left\langle R^{-6}\right\rangle\right)
\end{aligned}
$$

where $\left\langle R^{-6}\right\rangle=\int_{R_{\min }}^{\infty} R^{-6} f(R) d R$ and $K=C_{D A}\left\langle R^{-6}\right\rangle$ is the transfer rate expected for the localized $D^{*}-A$ energy transfer model. Using the same procedure for the acceptor transient, we obtain

$$
\bar{\phi}_{A}(t)=\exp \left(-t / \tau_{A}\right)-\exp \left(-t / \tau_{D}\right) \exp \left(-t C_{D A}\left\langle R^{-6}\right\rangle\right) .
$$

Considering that the localized interaction competes with the Inokuti-Hirayama interaction approach, one can have the final solution for the donor decay and the acceptor luminescence transient composed by the solutions expressed by Eqs. (7) and (9) (for the donor) and Eqs. (8) and (10) (for the acceptor), respectively given in the following:

$$
\bar{I}_{D}(t)=a \exp \left(-\frac{t}{\tau_{D}}-\gamma \sqrt{t}\right)+b \exp \left(-\frac{t}{\tau_{D}}-K t\right)
$$

[used in the $\operatorname{Tm}\left({ }^{3} \mathrm{H}_{4}\right)$ luminescence decay analysis] and

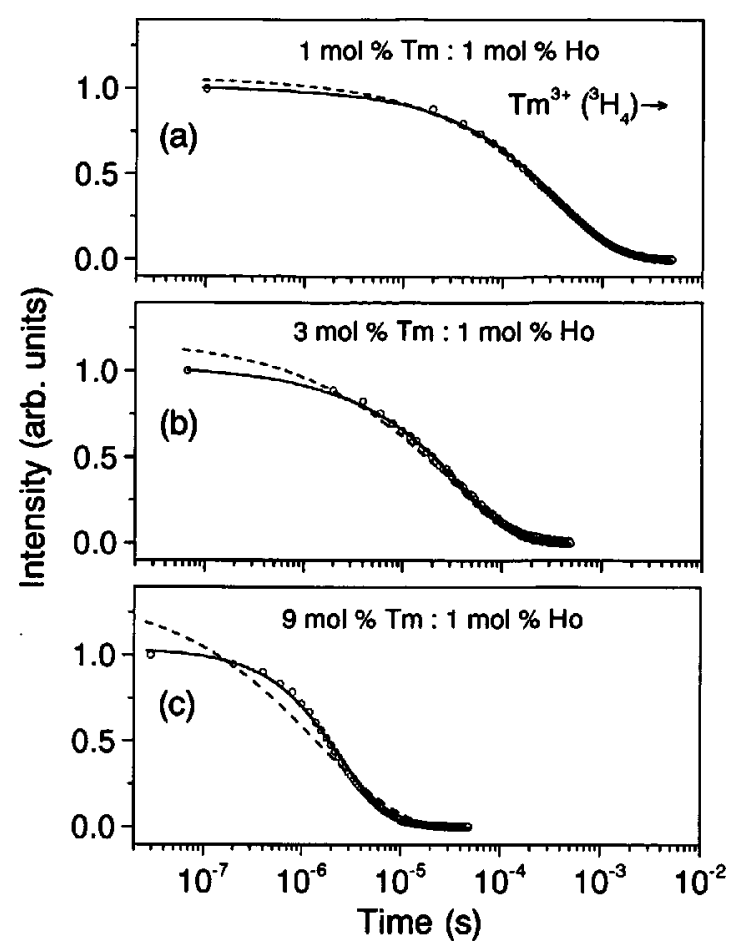

FIG. 8. Fluorescence decay of $\operatorname{Tm}\left({ }^{3} \mathrm{H}_{4}\right)$ at $1.47 \mu \mathrm{m}$ emission measured in $\operatorname{Tm}(x): \operatorname{Ho}(1 \%)$ :ZBLAN with three different Tm concentrations with $x$ $=1 \mathrm{~mol} \%$ (a), $x=3 \mathrm{~mol} \%$ (b), and $x=9 \mathrm{~mol} \%$ (c) (after laser excitation at $0.78 \mu \mathrm{m}$ ). The dashed lines were obtained from the best fit using the Inokuti-Hirayama solution for the donor (Tm) ion. The solid lines represent the best fit obtained using a solution that also includes the donor decay due to the localized $D^{*}-A$ interaction [according to Eq. (11)].

$$
\begin{aligned}
\bar{I}_{A}(t)= & a\left[\exp \left(-\frac{t}{\tau_{A}}\right)-\exp \left(-\frac{t}{\tau_{D}}-\gamma \sqrt{t}\right)\right] \\
& +b\left[\exp \left(-\frac{t}{\tau_{A}}\right)-\exp \left(-\frac{t}{\tau_{D}}-K t\right)\right]
\end{aligned}
$$

[used in the $\left.\mathrm{Ho}^{5}{ }^{5} \mathrm{I}_{7}\right)$ luminescence transient]. $a$ and $b$ in Eqs. (11) and (12) represent the non-normalized contribution of the Inokuti-Hirayama $(I)$ and the localized $D^{*}-A$ energy transfer $(T)$ solutions, respectively.

It is important to note that the final solutions for the donor and acceptor luminescence obtained were built with valid solutions of the localized and nonlocalized interactions (Inokuti-Hirayama) with no conflicting approach (i.e., both approaches do not include the diffusion among donors, but its apparent effect of acceptor concentration increase induced by the fast excitation diffusion). The Yokota-Tanimoto ${ }^{11}$ solution was not proper to use to compose the final solution of

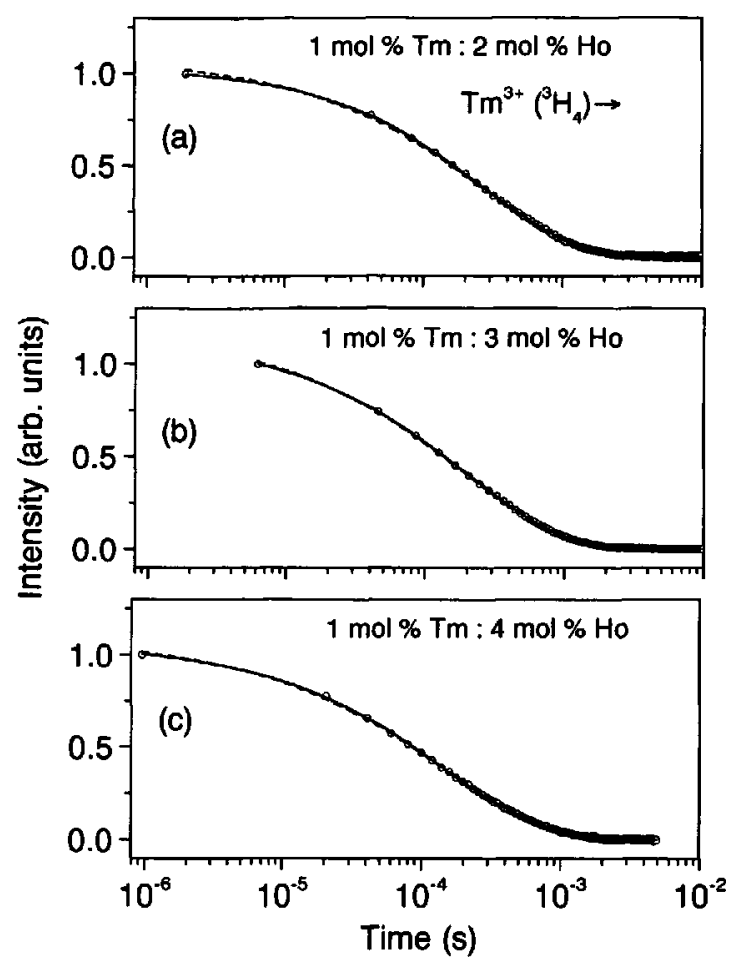

FIG. 9. Fluorescence decay of $\mathrm{Tm}\left({ }^{3} \mathrm{H}_{4}\right)$ at $1.47 \mu \mathrm{m}$ emission measured in $\operatorname{Tm}(1 \%): \operatorname{Ho}(y)$ :ZBLAN with three different Ho concentrations with $y$ $=2 \mathrm{~mol} \%$ (a), $y=3 \mathrm{~mol} \%$ (b), and $y=4 \mathrm{~mol} \%$ (c) (after laser excitation at $0.78 \mu \mathrm{m}$ ). The dashed lines were obtained from the best fit using the Inokuti-Hirayama solution for the donor $(\mathrm{Tm})$ ion and the solid lines were obtained using an expression that also includes the donor decay due to the localized $D^{*}-A$ interaction [Eq. (11)]. 
TABLE II. Experimental values of ET parameters obtained for the best fit of the $2-\mu \mathrm{m}$ luminescence of $\mathrm{Ho}^{3+}\left({ }^{5} \mathrm{I}_{7}\right)$ using Eq. (8) for the Inokuti-Hirayama (acceptor) and Eq. (12) for a solution that includes the localized $D^{*}-A$ interaction contribution for two sets of $\operatorname{Tm}(x)$ : $\operatorname{Ho}(y)$ :ZBLAN. Theoretic values of $\gamma$ parameters and $K_{d}$ were obtained from the microscopic theory of energy transfer based on the random walk problem involving excitation migration by diffusion through donors states (diffusion model).

\begin{tabular}{|c|c|c|c|c|c|c|c|c|c|c|}
\hline \multicolumn{2}{|c|}{$\begin{array}{l}\text { Tm:Ho: } \\
\text { ZBLAN } \\
(\operatorname{mol} \%)\end{array}$} & \multicolumn{2}{|c|}{$\begin{array}{l}\text { Transfer parameter } \\
\qquad\left(\mathrm{s}^{-1 / 2}\right)\end{array}$} & \multirow{2}{*}{$\begin{array}{c}K \\
\left(10^{3} \mathrm{~s}^{-1}\right) \\
(\mathrm{expt})^{\mathrm{b}}\end{array}$} & \multirow{2}{*}{$\begin{array}{c}a \\
(\mathrm{expt})^{\mathrm{b}}\end{array}$} & \multirow{2}{*}{$\begin{array}{c}b \\
(\mathrm{expt})^{\mathrm{b}}\end{array}$} & \multirow{2}{*}{$\begin{array}{c}K_{t} \\
\left(10^{3} \mathrm{~s}^{-1}\right) \\
(\mathrm{expt})^{\mathrm{c}}\end{array}$} & \multirow{2}{*}{$\begin{array}{c}K_{d} \\
\left(10^{3} \mathrm{~s}^{-1}\right) \\
(\text { theor })^{\mathrm{d}}\end{array}$} & \multirow{2}{*}{$\begin{array}{c}\tau_{\mathrm{Ho}} \\
(\mathrm{ms}) \\
(\operatorname{expt})^{\mathrm{b}}\end{array}$} & \multirow{2}{*}{$\begin{array}{c}\tau_{\mathrm{Tm}} \\
(\mu \mathrm{s}) \\
(\operatorname{expt})^{c}\end{array}$} \\
\hline$(x)$ & (y) & $\gamma(\text { theor })^{\mathrm{a}}$ & $\gamma(\text { expt })^{b}$ & & & & & & & \\
\hline 0.5 & 1 & 101.2 & $111.6 \pm 1.3$ & $412.0 \pm 2.7$ & 0.84 & 0.22 & 15.7 & 1.2 & $16.4 \pm 0.1$ & 63.8 \\
\hline 1 & 1 & 100.9 & $151.4 \pm 1.2$ & $308.8 \pm 1.4$ & 0.83 & 0.18 & 27.5 & 2.4 & $16.4 \pm 0.6$ & 36.4 \\
\hline 3 & 1 & 99.7 & $281.2 \pm 2.1$ & $162.8 \pm 2.7$ & 0.77 & 0.27 & 91.0 & 6.9 & $12.4 \pm 0.2$ & 11.0 \\
\hline 6 & 1 & 94.2 & $275.3 \pm 9.9$ & $221.9 \pm 2.1$ & 0.34 & 0.70 & 137.0 & 12.4 & $4.8 \pm 0.2$ & 7.3 \\
\hline 9 & 1 & 96.4 & $223.0 \pm 2.1$ & $316.3 \pm 2.5$ & 0.21 & 0.85 & 153.8 & 19.5 & $2.0 \pm 0.2$ & 6.5 \\
\hline 1 & 0.5 & 50.6 & $140.9 \pm 1.8$ & $127.0 \pm 4.4$ & 0.82 & 0.24 & 24.5 & 1.2 & $13.8 \pm 0.5$ & 40.8 \\
\hline 1 & 2 & 200.7 & $215.7 \pm 4.2$ & $184.3 \pm 3.0$ & 0.53 & 0.49 & 72.5 & 4.7 & $15.4 \pm 0.6$ & 13.8 \\
\hline 1 & 3 & 299.3 & $280.6 \pm 8.1$ & $289.7 \pm 3.3$ & 0.38 & 0.64 & 145.0 & 6.9 & $15.8 \pm 0.7$ & 6.9 \\
\hline 1 & 4 & 396.9 & $281.0 \pm 15$ & $389.9 \pm 3.3$ & 0.27 & 0.76 & 188.7 & 9.2 & $12.5 \pm 1.7$ & 5.3 \\
\hline
\end{tabular}

${ }^{a}$ Calculated values using the Inokuti-Hirayama theory (Ref. 7). Deviation estimation of these calculated parameters was 10\% considering the propagation error in the absorption measurements.

${ }^{b}$ Experimental data obtained from the best fit of the acceptor luminescence transient described by Eq. (8).

cObtained from Eq. (12).

${ }^{\mathrm{d} C a l c u l a t e d ~ v a l u e s ~ u s i n g ~ t h e ~ d i f f u s i o n ~ m o d e l ~(R e f . ~ 11) . ~ D e v i a t i o n ~ e s t i m a t i o n ~ o f ~ t h e s e ~ c a l c u l a t e d ~ p a r a m e t e r s ~ w a s ~} 10 \%$ considering the propagation error in the absorption measurements.

the donor and acceptor luminescence transients because it is valid only for the cases where the diffusion process is considered a perturbation in the direct $D^{*}-A$ energy transfer, which is not the case in this work because the fast excitation diffusion cannot be assumed as a perturbation, but it causes the main physical effect.

The normalized fractions of each contribution $I$ and $T$, respectively, for the Inokuti-Hirayama and localized $D^{*}-A$ energy transfer solutions were obtained using that

$$
I=\frac{a}{a+b}, \quad T=\frac{b}{a+b} .
$$

Considering the proposed model, the mean decay time of donor $\left(\mathrm{Tm}^{3+}\right)$ fluorescence is obtained using the expression

$$
\tau_{\mathrm{Tm}}=\frac{\int_{0}^{\infty} \bar{I}_{D}(t) d t}{\bar{I}_{D}(0)},
$$

where $\bar{I}_{D}(0)=a+b$, given

$$
K_{t}(\exp )=\tau_{\mathrm{Tm}}^{-1}=\left[\left(\frac{a}{a+b}\right)\left(\frac{1}{\gamma^{2}}\right)+\left(\frac{b}{a+b}\right)\left(\frac{1}{K}\right)\right]^{-1} .
$$

Figures 6 and 7 show the best fit of 2- $\mu$ m Ho luminescence by laser excitation of the $\mathrm{Tm}^{3+}\left({ }^{3} \mathrm{~F}_{4}\right)$ state at 1.67 $\mu \mathrm{m}$. Figures 8 and 9 show the best fit of $1.47-\mu \mathrm{m}$ Tm luminescence by laser excitation of the $\mathrm{Tm}^{3+}\left({ }^{3} \mathrm{H}_{4}\right)$ state at 0.78 $\mu \mathrm{m}$. The 1.67- $\mu \mathrm{m}(\mathrm{Tm})$ and $2-\mu \mathrm{m}(\mathrm{Ho})$ luminescence transients are better described using the solution given by Eqs. (11) and (12), respectively, in which the localized $D^{*}-A$ energy transfer solution takes part. The best fit parameters of $\mathrm{Tm} \rightarrow$ Ho ET obtained from the $\mathrm{Ho}^{3+}\left({ }^{5} \mathrm{I}_{7}\right)$ luminescence curve fitting using Eq. (12) and the predicted values of $\gamma$ (theor) and $K_{d}$ (from the diffusion model) are given in Table II. There it is seen that $\gamma($ expt $)$ and $K($ expt) are always bigger than $\gamma$ (theor) predicted by the Inokuti-Hirayama approach [given by Eq. (14)]. Consequently, the experimental values of the transfer rate $\gamma^{2}$ (expt) are always much bigger than the transfer rate $\left(K_{d}\right)$ predicted from the diffusion model [given by Eq. (15)]. The obtained fitting parameters for the case of $\operatorname{Tm}\left({ }^{3} \mathrm{H}_{4}\right)$ luminescence decay analysis using Eq. (11) are given in Table III. Theoretical values of the transfer rate predicted by the Inokuti-Hirayama model $(\gamma)$ can be calculated using the expression

$$
\gamma(\text { theor })=\frac{4 \pi^{3 / 2}}{3} c_{A}\left(C_{D A}\right)^{1 / 2} .
$$

Any diffusing excitation by an electric dipole-dipole interaction between donors on a cubic lattice has a trapping radius defined as the distance at which the $D \rightarrow A$ transfer rate is equal to the rate of $D \rightarrow D$ transfer. This gives $R_{T}$ $=0.676\left(C_{D A} / D\right)^{1 / 4}$. The diffusion coefficient $\left(\mathrm{cm}^{2} / \mathrm{s}\right)$ is given by $D=\frac{1}{2}\left(4 \pi c_{D} / 3\right)^{4 / 3} c_{D D}$ and the energy transfer rate, which is associated with excitation diffusion and trapping (here is assumed an unit trapping efficiency) derived from the random walk treatment, ${ }^{11}$ is given by $K_{D}=4 \pi D R_{T} c_{A}$. This can be related to the microscopic parameters of the interaction by

$$
K_{d}=21 c_{A} c_{D}\left(C_{D D}^{3} C_{D A}\right)^{1 / 4},
$$

where $c_{A}$ is the acceptor concentration ( $\mathrm{Ho}$ ) for the $\mathrm{Tm}$ $\rightarrow$ Ho ET and (Tm) for the $\mathrm{Tm} \rightarrow \mathrm{Tm} \mathrm{CR}$, and $c_{D}$ is the donor concentration $(\mathrm{Tm})$ for the $\mathrm{Tm} \rightarrow \mathrm{Ho}$ ET and $\mathrm{Tm} \rightarrow \mathrm{Tm} \mathrm{CR}$. The theoretical values of $\gamma$ and $K_{d}$ transfer parameters were calculated for the Tm-Ho ET and $\mathrm{Tm}-\mathrm{Tm} \mathrm{Cr}$ and are given in Tables II and III for comparison with the experimental values. A moderate decrease of the measured lifetime of the ${ }^{5} \mathrm{I}_{7}\left(\mathrm{Ho}^{3+}\right)$ state in $\mathrm{Tm}(x): \mathrm{Ho}(1 \%)$ samples with $\mathrm{Tm}^{3+}$ concentration increase $(x=1-9 \mathrm{~mol} \%)$ was observed in Table II. This lifetime decrease (from 16 to $2 \mathrm{~ms}$ ) was attributed to the upconversion of the ${ }^{5} \mathrm{I}_{7}$ state by an energy transfer mechanism (ETU) involving the ${ }^{3} \mathrm{~F}_{4}$ state of $\mathrm{Tm}^{3+}$ (see schematic diagram of Fig. 10). Excited-state absorption (ESA) 
TABLE III. Experimental values of ET parameters obtained for the best fit of the 1.47- $\mu \mathrm{m}$ luminescence of $\mathrm{Tm}^{3+}\left({ }^{3} \mathrm{H}_{4}\right)$ using Eq. (7) for the InokutiHirayama (donor) and Eq. (11) that includes the solution of the localized $D^{*}-A$ interaction contribution for two $\operatorname{sets}$ of $\operatorname{Tm}(x): \operatorname{Ho}(y)$ :ZBLAN. Theoretic values of $\gamma$ parameters and $K_{d}$ were obtained from the microscopic theory of energy transfer based on the random walk problem involving excitation migration by diffusion through donors states (diffusion model).

\begin{tabular}{|c|c|c|c|c|c|c|c|c|c|}
\hline \multicolumn{2}{|c|}{$\begin{array}{l}\text { Tm:Ho } \\
(\mathrm{mol} \%)\end{array}$} & \multicolumn{2}{|c|}{$\begin{array}{c}\text { Transfer parameter } \\
\qquad\left(\mathrm{s}^{-1 / 2}\right)\end{array}$} & \multirow{2}{*}{$\begin{array}{c}K \\
\left(10^{3} \mathrm{~s}^{-1}\right) \\
(\mathrm{expt})^{\mathrm{b}}\end{array}$} & \multirow{2}{*}{$\begin{array}{c}a \\
(\mathrm{expt})^{\mathrm{b}}\end{array}$} & \multirow{2}{*}{$\begin{array}{c}b \\
(\operatorname{expt})^{b}\end{array}$} & \multirow{2}{*}{$\begin{array}{c}K_{t} \\
\left(10^{3} \mathrm{~s}^{-1}\right) \\
(\mathrm{expt})^{\mathrm{c}}\end{array}$} & \multirow{2}{*}{$\begin{array}{c}K_{d} \\
\left(10^{3} \mathrm{~s}^{-1}\right) \\
(\text { theor })^{\mathrm{d}}\end{array}$} & \multirow{2}{*}{$\begin{array}{c}\tau_{\mathrm{Tm}} \\
(\mu \mathrm{s}) \\
(\mathrm{expt})^{\mathrm{c}}\end{array}$} \\
\hline$(x)$ & (y) & $\gamma(\text { theor })^{\mathrm{a}}$ & $\gamma(\operatorname{expt})^{b}$ & & & & & & \\
\hline 0.5 & 0 & 6.8 & $12.1 \pm 0.4$ & $1.8 \pm 0.1$ & 0.95 & 0.05 & 0.15 & 0.08 & 6660.8 \\
\hline 0.5 & 1 & 6.8 & $11.9 \pm 0.4$ & $1.9 \pm 0.1$ & 0.92 & 0.09 & 0.16 & 0.08 & 6420.3 \\
\hline 1 & 1 & 13.6 & $40.2 \pm 0.4$ & $3.3 \pm 0.9$ & 0.82 & 0.20 & 1.79 & 0.33 & 559.7 \\
\hline 3 & 1 & 40.4 & $182 \pm 4.0$ & $25.0 \pm 0.7$ & 0.64 & 0.40 & 29.5 & 2.9 & 33.9 \\
\hline 6 & 1 & 76.4 & $357 \pm 11$ & $153.2 \pm 1.6$ & 0.31 & 0.73 & 145 & 10.3 & 6.9 \\
\hline 9 & 1 & 117.2 & $231.5 \pm 7.6$ & $395.6 \pm 2.5$ & 0.09 & 0.97 & 256.4 & 24.3 & 3.9 \\
\hline 1 & 0.5 & 13.7 & $42.3 \pm 0.6$ & $2.7 \pm 0.2$ & 0.88 & 0.16 & 1.89 & 0.33 & 529.9 \\
\hline 1 & 2 & 13.6 & $53.3 \pm 0.6$ & $2.4 \pm 0.2$ & 0.96 & 0.11 & 2.79 & 0.33 & 358.2 \\
\hline 1 & 3 & 13.5 & $66.6 \pm 0.4$ & $3.4 \pm 0.2$ & 1.11 & 0.07 & 4.36 & 0.32 & 229.2 \\
\hline 1 & 4 & 13.4 & $73.3 \pm 0.7$ & $10.3 \pm 0.7$ & 0.98 & 0.09 & 33.6 & 0.32 & 178.5 \\
\hline
\end{tabular}

${ }^{a}$ Calculated values using the Inokuti-Hirayama theory (Ref. 7). Deviation estimation of these calculated parameters was 10\% considering the propagation error in the absorption measurements.

bexperimental data obtained from the best fit of the donor luminescence and rate equation given by Eq. (7).

'Obtained from Eq. (11).

${ }^{\mathrm{d} C a l c u l a t e d ~ v a l u e s ~ u s i n g ~ t h e ~ d i f f u s i o n ~ m o d e l ~(R e f . ~ 11) . ~ D e v i a t i o n ~ e s t i m a t i o n ~ o f ~ t h e s e ~ c a l c u l a t e d ~ p a r a m e t e r s ~ w a s ~} 10 \%$ considering the propagation error in the absorption measurements.

can not account for this observed upconversion effect because it occurs in a much longer time $(\sim 2.3 \mathrm{~ms})$ than the laser pulse (4 ns). For samples of set (ii), $\operatorname{Tm}(1 \%): \operatorname{Ho}(y): Z B L A N$ where $y=0,0.5,2,3,4 \mathrm{~mol} \%$, the lifetime of ${ }^{5} \mathrm{I}_{7}\left(\mathrm{Ho}^{3+}\right)$ is within 15 and $16 \mathrm{~ms}$ (see data of Table II). However, a small reduction of this lifetime is observed for the cases when the $\mathrm{Ho}^{3+}$ concentration is higher than $3 \mathrm{~mol} \%$. In addition, we observed for the samples of set (ii) a small reduction of the luminescence lifetime of the ${ }^{3} \mathrm{H}_{4}\left(\mathrm{Tm}^{3+}\right)$ state with an increase of $\mathrm{Ho}^{3+}$ concentration (see data of Table III). This suggests that a small fraction of $\mathrm{Tm}^{3+}$ ions in the ${ }^{3} \mathrm{H}_{4}$ state can transfer energy to the ${ }^{5} \mathrm{I}_{5}$ state of $\mathrm{Ho}^{3+}$.

The results presented in Tables II and III showed that the best fit values of the $\gamma$ parameter [or $\gamma(\operatorname{expt})]$ is always higher than the predict value of $\gamma$ by the Inokuti-Hirayama model [or $\gamma$ (theor)] for the Tm $\rightarrow$ Ho ET. The results observed for the Tm $\rightarrow$ Ho ET and presented in Table II confirm the existence of fast excitation diffusion among donor $\left(\mathrm{Tm}^{3+}\right)$ ions before energy transfer to the acceptor $\left(\mathrm{Ho}^{3+}\right)$. A similar conclusion was also obtained when observing the

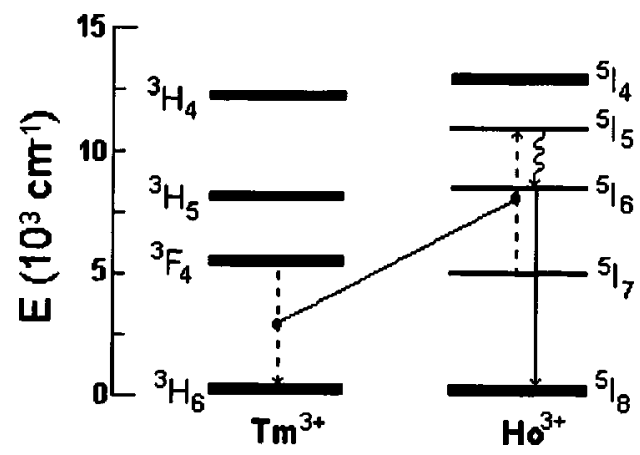

FIG. 10. Schematic energy level diagram showing the energy transfer by upconversion (ETU mechanism) involving Tm and Ho ions after Tm excitation at $0.78 \mu \mathrm{m}$ in Tm:Ho:ZBLAN. results of $\mathrm{Tm} \rightarrow \mathrm{Tm}$ cross relaxation exhibited in Table III. These two ET processes-Tm-Ho ET and Tm-Tm CRhave an experimental transfer rate $K_{t}$ (expt) about 40 times bigger than the transfer rate $\left(K_{d}\right)$ predicted by the diffusion model. ${ }^{11}$ Based on this observation, we concluded that the Tm-Ho ET and Tm-Tm CR are a fast-excitation diffusiondependent energy transfer mechanism similar to the one observed for the $\mathrm{Yb} \rightarrow \mathrm{Er}$ energy transfer in ZBLAN glass. ${ }^{8} \mathrm{As}$ a consequence, the hypothesis on the occurrence of fast excitation diffusion occurrence before the direct $D^{*}-A$ resonant energy transfer is reinforced.

\section{DISCUSSION AND CONCLUSIONS}

In this work the transfer parameter $K_{d}$ was obtained independently of solving the diffusion-assisted energy transfer equation (which has no analytical solution) from the random walk problem description, Eq. (15). This transfer rate value gives the highest limit of the transfer rate for a randomexcitation migration-assisted energy transfer and is valuable for comparison with the experimental (and theoretical) transfer rates $\gamma^{2}$ (or $K$ ) to evidence the existence of a fast excitation diffusion among donors as the main diffusion mechanism responsible for the highest values observed for the $\mathrm{Tm} \rightarrow \mathrm{Tm}$ and $\mathrm{Tm} \rightarrow$ Ho transfer rates. The analysis of the luminescence decay of $\operatorname{Tm}\left({ }^{3} \mathrm{H}_{4}\right)$ at $1.47 \mu \mathrm{m}$ and $\operatorname{Tm}\left({ }^{3} \mathrm{~F}_{4}\right)$ at $1.8 \mu \mathrm{m}$ in low single-doped $\operatorname{Tm}(0.5 \mathrm{~mol} \%)$ :ZBLAN showed that the Inokuti-Hirayama model (donor solution for a dipole-dipole interaction) gives good fitting of the luminescence transient with transfer parameter $\gamma($ expt) equal to 12.2 $\mathrm{s}^{-1 / 2}$, which is higher than the expected value $\gamma$ (theor) $=6.8 \mathrm{~s}^{-1 / 2}$ [see data of Table III (first row)]. This result shows that the fast excitation diffusion is already present in this case of low $\mathrm{Tm}^{3+}$ concentration besides the InokutiHirayama model, indicating that the migration is not occurring (for dipole-dipole interactions, $s=6$ ). In this case, the 
luminescence behavior is described by $95 \%$ (a) of the Inokuti-Hirayama contribution and 5\% (b) by the exponential term. The luminescence decays of ${ }^{3} \mathrm{~F}_{4}$ and ${ }^{5} \mathrm{I}_{7}$ excited states of $\mathrm{Tm}$ and $\mathrm{Ho}$ ions in $\mathrm{Tm}(0.5 \mathrm{~mol} \%)$ and $\mathrm{Ho}(0.5$ mol \%):ZBLAN were observed be pure exponentials with lifetimes of 8.9 and $16.4 \mathrm{~ms}$, respectively. The use of a dipole-dipole $(s=6)$ interaction for the energy transfer cases and systems used in this work is justified because the concentration level of dopants is not high enough to evidence the higher order of dipole interactions (i.e., [Tm] and [Ho] $\leqslant 6 \mathrm{~mol} \%)$. We have observed that a dipole-dipole $(s=6)$ interaction dominates the $\mathrm{Er}-\mathrm{Er}$ cross-relaxation process involving ${ }^{4} \mathrm{~S}_{3 / 2}$ and ${ }^{4} \mathrm{I}_{15 / 2}$ in YLF crystals (and Er:ZBLAN glasses) for Er concentration up to $20 \mathrm{~mol} \%$. Deviation from the Inokuti-Hirayama donor solution for the dipole-dipole $(s=6)$ interaction starts when the Er concentration reaches 40 mol \% YLF crystals. In this case, a fast component decay of the ${ }^{4} \mathrm{~S}_{3 / 2}$ excited state appears and the fitting has to consider the Inokuti-Hirayama donor solutions for dipoledipole and dipole-quadrupole $(s=8)$ interactions. However, the main contribution still comes from the dipole-dipole interaction.

The results on the luminescence decay of ${ }^{5} \mathrm{I}_{7}\left(\mathrm{Ho}^{3+}\right)$ at $\sim 2 \mu \mathrm{m}$ and ${ }^{3} \mathrm{H}_{4}\left(\mathrm{Tm}^{3+}\right)$ at $\sim 1.5 \mu \mathrm{m}$ showed that the $\mathrm{Tm}$ $\rightarrow$ Ho ET is dominated by the acceptor luminescence solution based on the Inokuti-Hirayama model, while both Tm $\rightarrow \mathrm{Tm} \mathrm{CR}$ and $\left({ }^{3} \mathrm{H}_{4}\right) \mathrm{Tm} \rightarrow \mathrm{Tm}$ migrations are dominated by the donor solution of the Inokuti-Hirayama model. The experimental transfer parameter $\gamma($ expt $)$ is larger than predicted by diffusion theory for the two-sample set of codoped Tm:Ho:ZBLAN samples. This fact corroborates the assumption that a fast excitation diffusion modifies the excitation distribution among excited donors and acceptor ions produced initially by laser excitation at $t=0$. After the excitation diffusion, two types of $D^{*}-A$ interaction are expected. First, one expects a $D^{*}-A$ interaction where $D^{*}$ interacts with all the acceptors inside of the interaction volume $V$ leading to the Inokuti-Hirayama-type solution (contribution fraction $A)$. Second, the $D^{*}$ ion can transfer its excitation to the nearest-neighbor $A$ ion, giving rise to the exponential decay (localized $D^{*}-A$ interaction). The $a$ and $b$ parameters obtained from the best fit using Eq. (11) for ${ }^{3} \mathrm{H}_{4}\left(\mathrm{Tm}^{3+}\right)$ luminescence at $\sim 1.5 \mu \mathrm{m}$ [or Eq. (12) for ${ }^{5} \mathrm{I}_{7}\left(\mathrm{Ho}^{3+}\right)$ luminescence at $\sim 2 \mu \mathrm{m}]$ can be also calculated assuming the existence of a critical radius $\left(R_{C}\right)$ and using the distribution function $f(R) d R$ between $D$ and $A$ ions and assuming that a localized $D^{*}-A$ energy transfer occurs only if $D^{*}-A$ pairs are separated by a distance $R<R_{C}$. On the other hand, the Inokuti-Hirayama transfer predominates in the case of $R$ $>R_{C}$. Obviously, one must assume the opposite for the case of a localized $D^{*}-A$ interaction. According to this,

$$
\begin{aligned}
& I=\int_{R_{C}}^{\infty} f(R) d R=\exp \left(\frac{-4 \pi c_{A}^{\prime}}{3}\left(R_{C}^{3}-R_{m}^{3}\right)\right), \\
& T=1-\exp \left(\frac{-4 \pi c_{A}^{\prime}}{3}\left(R_{C}^{3}-R_{m}^{3}\right)\right),
\end{aligned}
$$

where $R_{m}$ is the minimum distance between rare-earth ions in ZBLAN estimated to be equal to $3.78 \AA$. Here $c_{A}^{\prime}$ is the
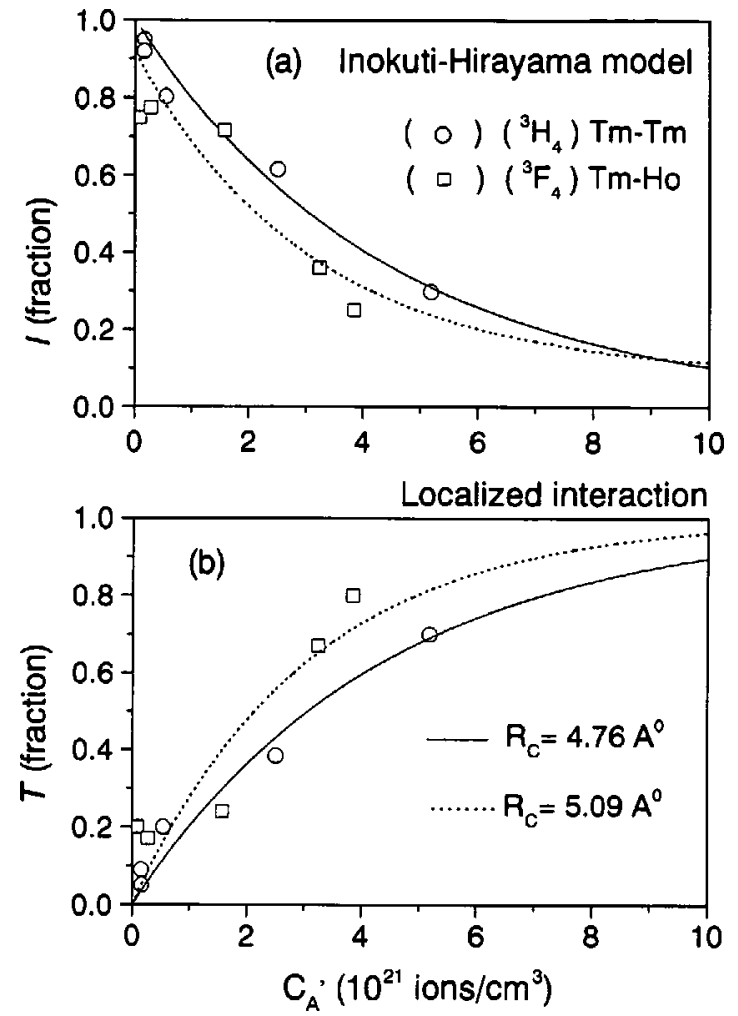

FIG. 11. Inokuti-Hirayama (I) and localized $D^{*}-A$ interaction $(T)$ contributions observed in $\operatorname{Tm}(x \%): \operatorname{Ho}(1 \%)$ :ZBLAN after laser excitation. (a) shows the contribution $(I)$ for the $\left({ }^{3} \mathrm{H}_{4}\right)$ Tm-Tm cross-relaxation process (open circles) and for $\mathrm{Tm} \rightarrow$ Ho ET (open squares). (b) shows the contribution $(T)$ of the localized $D^{*}-A$ interaction that occurs after the fast excitation diffusion, for the above interaction systems. The solid and dotted lines represent the best fit obtained using Eqs. (16) [(a)] and (17) [(b)]. $c_{A}^{\prime}$ is the apparent acceptor concentration calculated using the ratio between the experimental and theoretical values of the energy transfer constant $(\gamma)$.

apparent acceptor concentration felt by the donor after the fast excitation diffusion occurrence that modified the initial $D^{*}-A$ distribution. This apparent acceptor concentration $\left(c_{A}^{\prime}\right)$ was obtained from the relation $c_{A}^{\prime} / c_{A}$ $=\gamma(\operatorname{expt}) / \gamma$ (theor). Figure 11(a) exhibits the InokutiHirayama contribution (I) due to the fast excitation diffusion for the $\left({ }^{3} \mathrm{H}_{4}\right) \mathrm{Tm}-\mathrm{Tm} \mathrm{CR}$ (open circles) and $\mathrm{Tm} \rightarrow \mathrm{Ho}$ ET (open squares) as a function of the apparent acceptor concentration $\left(c_{A}^{\prime}\right)$ for set (i) $[\operatorname{Tm}(x): \operatorname{Ho}(1 \%): Z B L A N]$. Figure 11(b) exhibits the data for the $D^{*}-A$ localized interaction contribution $(T)$. The solid and dotted lines were used for representing the best fit of the data of $\left({ }^{3} \mathrm{H}_{4}\right) \mathrm{Tm}-\mathrm{Tm}$ and $\left({ }^{3} \mathrm{~F}_{4}\right)$ Tm-Ho interactions, respectively. The results show that the critical radius that triggers the localized $\left({ }^{3} \mathrm{H}_{4}\right)$ $\mathrm{Tm}-\mathrm{Tm}$ interaction is equal to $4.76 \AA$ [and $R_{c}=5.09 \AA$ for the $\left({ }^{3} \mathrm{~F}_{4}\right) \mathrm{Tm}-\mathrm{Ho}$ interaction].

Table IV shows $I$ and $T$ values obtained from ${ }^{5} \mathrm{I}_{7}\left(\mathrm{Ho}^{3+}\right)$ luminescence at $\sim 2 \mu \mathrm{m}$ and $I$ and $T$ values obtained from ${ }^{3} \mathrm{H}_{4}\left(\mathrm{Tm}^{3+}\right)$ luminescence at $\sim 1.5 \mu \mathrm{m}$. The values of $I$ and $T$ were plotted as a function of $\mathrm{Tm}^{3+}$ concentration $(x$ $=0.5,1,3,6$, and $9 \mathrm{~mol} \%$ ), as well as a function of the total $[\operatorname{Tm}(x)]+[\operatorname{Ho}(y)]$ concentration $[$ or $(x+y)=1.5,2,3,5,7$, and $10 \mathrm{~mol} \%$ ]. These plots are shown in Figs. 12(a) and 12(b) using $I$ and $T$ obtained from a best fit of Ho emission at $2 \mu \mathrm{m}$. Figures 13(a) and 13(b) were obtained using $I$ and $T$ 
TABLE IV. Normalized contribution of Inokuti-Hirayama $(I)$ and localized $D^{*}-A$ interaction contribution $(T)$ calculated from $a$ and $b$ best fit values used in Eqs. (11) and (12).

\begin{tabular}{|c|c|c|c|c|c|}
\hline \multicolumn{2}{|c|}{ 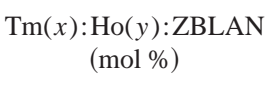 } & \multicolumn{2}{|c|}{$\begin{array}{c}\mathrm{Ho}^{3+}\left({ }^{5} \mathrm{I}_{7}\right) \text { luminescence } \\
(2 \mu \mathrm{m})\end{array}$} & \multicolumn{2}{|c|}{$\begin{array}{c}\mathrm{Tm}^{3+}\left({ }^{3} \mathrm{H}_{4}\right) \text { luminescence } \\
(1.47 \mu \mathrm{m})\end{array}$} \\
\hline$x$ & $y$ & $I^{\mathrm{a}}$ & $T^{\mathrm{b}}$ & $I^{\mathrm{a}}$ & $T^{\mathrm{b}}$ \\
\hline 0.5 & 0 & - & - & 0.95 & 0.05 \\
\hline 0.5 & 1 & 0.79 & 0.21 & 0.91 & 0.09 \\
\hline 1 & 1 & 0.82 & 0.18 & 0.81 & 0.19 \\
\hline 3 & 1 & 0.74 & 0.26 & 0.62 & 0.38 \\
\hline 6 & 1 & 0.33 & 0.68 & 0.30 & 0.70 \\
\hline 9 & 1 & 0.20 & 0.81 & 0.08 & 0.92 \\
\hline 6 & 0.1 & 0.78 & 0.23 & 0.85 & 0.15 \\
\hline 6 & 1 & 0.52 & 0.48 & 0.90 & 0.10 \\
\hline 6 & 3 & 0.37 & 0.63 & 0.94 & 0.06 \\
\hline 6 & 5 & 0.26 & 0.74 & 0.92 & 0.08 \\
\hline
\end{tabular}

${ }^{\mathrm{a}}$ Normalized fraction contribution of the Inokuti-Hirayama solution for the acceptor and donor luminescence, respectively, calculated from $a$ and $b$ best fit values.

${ }^{b}$ Normalized fraction contribution of the localized $D^{*}-A$ interaction for the acceptor and donor luminescence, respectively, calculated from $a$ and $b$ best fit values.

obtained from a best fit of Tm emission at $1.47 \mu \mathrm{m}$. Both figures show that when the $\left[\mathrm{Tm}^{3+}\right]$ or $\left(\left[\mathrm{Tm}^{3+}\right]+\left[\mathrm{Ho}^{3+}\right]\right)$ concentration increases, the contribution of the rate equation solution $(T)$ also increases and the Inokuti-Hirayama contribution ( $I$ ) decreases ( $I$ equals $T$ for $\mathrm{Tm}^{3+}=4.5 \mathrm{~mol} \%$ ). This result is consistent with the assumption that for lowconcentrated systems fast excitation diffusion can produce a less localized $D^{*}-A$ interaction: i.e., in this case, we have $I>T$. The increase of the $\mathrm{Tm}^{3+}$ or $\mathrm{Ho}^{3+}$ concentration favors the production of $D^{*}-A$ pairs having a separation distance $R \leqslant R_{C}$ leading to the case of $T>I$.
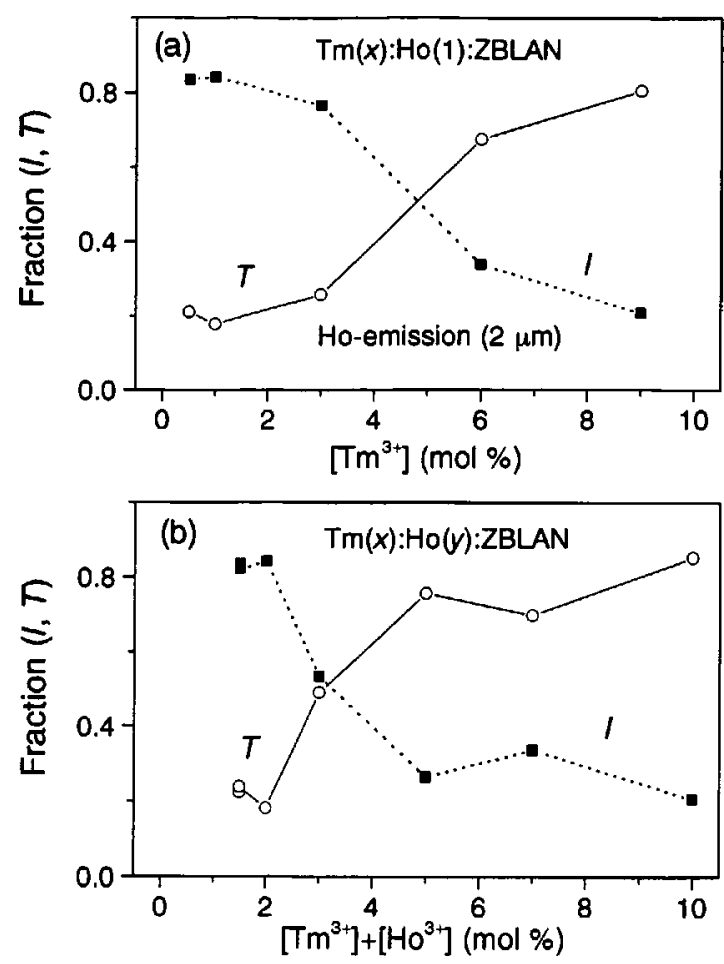

FIG. 12. Normalized fraction of Inokuti-Hirayama (I) and localized $D^{*}-A$ interaction $(T)$ contributions to the Ho luminescence transient (at $2 \mu \mathrm{m}$ ) in $\operatorname{Tm}(x \%): \operatorname{Ho}(1 \%): Z B L A N$ as a function of $\mathrm{Tm}$ concentration [(a)] or $[\mathrm{Tm}]+[\mathrm{Ho}]$ (total) concentration $[(\mathrm{b})]$.
The $\mathrm{Tm} \rightarrow$ Ho ET process that is strongly dependent on fast excitation diffusion also can be analyzed by looking its efficiency $(\eta)$ as a function of the Tm (donor) and Ho (acceptor) concentrations. This $\mathrm{Tm} \rightarrow$ Ho ET process-called here the ET1 process - competes with the Tm $\rightarrow$ Ho energy transfer assisted by diffusion migration according to the diffusion model (ET2 process), giving the following expressions for the $\eta(\mathrm{ET} 1)$ efficiency:

$$
\eta(\mathrm{ET} 1)=\frac{K(\mathrm{ET} 1)}{K(\mathrm{ET} 1)+K(\mathrm{ET} 2)},
$$
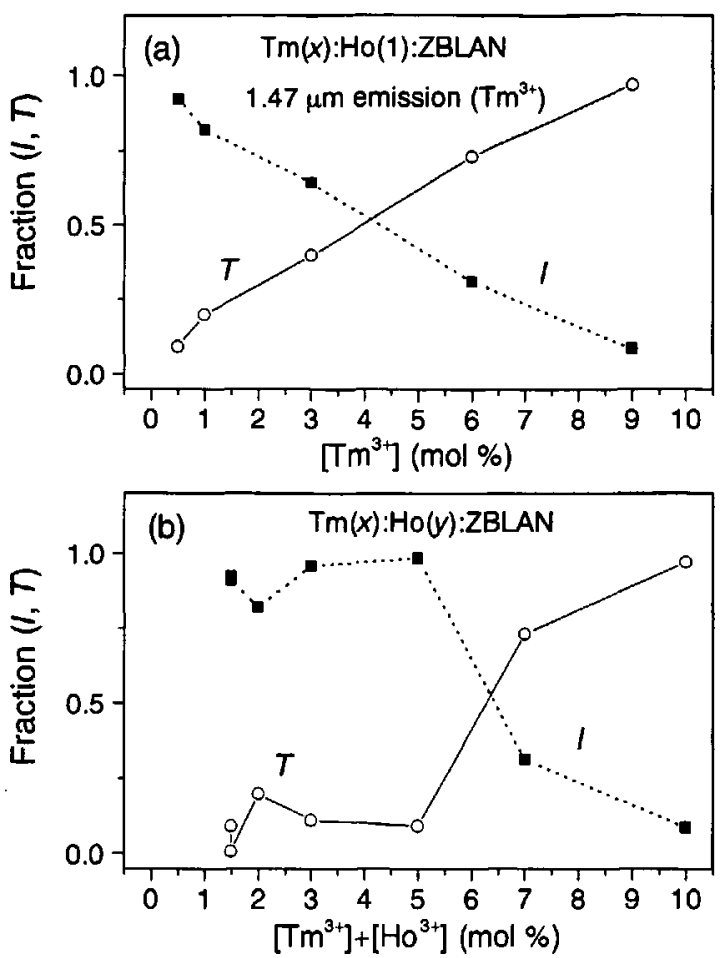

FIG. 13. Normalized fraction of Inokuti-Hirayama (I) and localized $D^{*}-A$ interaction $(T)$ contributions to the Tm luminescence decay (at $1.47 \mu \mathrm{m}$ ) in $\operatorname{Tm}(x \%): \mathrm{Ho}(1 \%): Z B L A N$ as a function of Tm concentration [(a)] or $[\mathrm{Tm}]+[\mathrm{Ho}]$ (total) concentration $[(\mathrm{b})]$. 

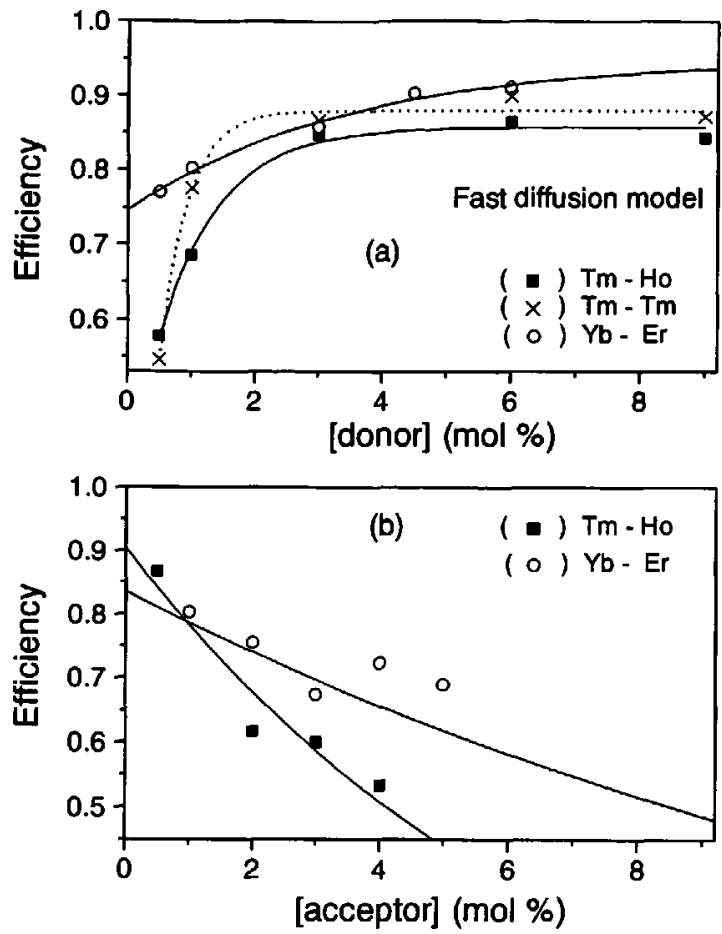

FIG. 14. Energy transfer efficiency calculated for $\mathrm{Tm} \rightarrow \mathrm{Ho}$ ET after the fast excitation diffusion (ET1 process) as a function of Tm concentration (or Er concentration in the case of $\mathrm{Yb}-\mathrm{Er}$ ET) [see (a)]. Solid squares represent the experimental data obtained for $\mathrm{Tm}-\mathrm{Ho}$ system, crossings represent the data of $\mathrm{Tm}-\mathrm{Tm}$ cross relaxation (CR), and open circles were used for $\mathrm{Yb} \rightarrow \mathrm{Er}$ ET (obtained from Ref. 8). The solid and dashed lines of (a) represent the best fit obtained using the fast diffusion model described by Eq. (19) in the case where of $c_{A}=1 \mathrm{~mol} \%$. (b) exhibits the efficiency [ $\left.\eta(\mathrm{ET} 1)\right]$ as function of acceptor concentration (Ho in the case of $\mathrm{Tm}: \mathrm{Ho}$ and $\mathrm{Er}$ in the case of $\mathrm{Yb}$ :Er systems). The solid lines of (b) were obtained from the best fit of Eq. (19) using a fixed donor concentration $\left(c_{D}=1 \mathrm{~mol} \%\right)$.

$$
\begin{aligned}
& K(\text { ET1 })=K_{t}(\text { expt }) \\
& K(\text { ET2 })=\gamma^{2}(\text { theor })+K_{d},
\end{aligned}
$$

where $K_{t}\left(\right.$ expt) was calculated using Eq. (13) and $\gamma^{2}$ (theor) and $K_{d}$ were calculated using Eqs. (14) and (15), respectively. Figure 14(a) shows the calculated efficiency of the $\mathrm{Tm} \rightarrow \mathrm{Tm}$ CR (crossing symbols) and Tm $\rightarrow$ Ho ET (squares symbols) as a function of $\mathrm{Tm}^{3+}$ concentration (and fixing $\mathrm{Ho}^{3+}$ at $1 \mathrm{~mol} \%$ ). The $\mathrm{Yb} \rightarrow$ Er energy transfer efficiencies are also plotted (open circles) as a function of $\left[\mathrm{Yb}^{3+}\right]$ concentration obtained for $\mathrm{Yb}$ :Er:ZBLAN glasses (and fixing the $\left[\mathrm{Er}^{3+}\right]$ at $1 \mathrm{~mol} \%$ ) (Ref. 8) for comparison. Figure 14(b) shows the $\mathrm{Tm} \rightarrow$ Ho ET efficiency dependence on the $\mathrm{Ho}^{3+}$ concentration observed for Tm:Ho:ZBLAN with the $\left[\mathrm{Tm}^{3+}\right]$ fixed at $1 \mathrm{~mol} \%$. In Fig. 14(a) it can be observed that the ET1 efficiency always dominates the ET process-i.e., $\eta$ $>0.5$ for $\mathrm{Tm} \rightarrow \mathrm{Tm} \mathrm{CR}$ and $\mathrm{Tm} \rightarrow$ Ho ET as first observed for the $\mathrm{Yb} \rightarrow \mathrm{Er}$ ET in Yb:Er:ZBLAN (where $\eta>0.76$ ). Tm $\rightarrow$ Tm cross relaxation exhibits a more drastic efficiency decrease with the Tm concentration decreasing below 2 mol \%. The observed behavior of the ET1 efficiency for $\mathrm{Tm} \rightarrow \mathrm{Tm}$ $\mathrm{CR}$ and $\mathrm{Tm} \rightarrow$ Ho ET in Tm:Ho:ZBLAN suggests that the fast excitation diffusion mechanism is similar to the one observed in $\mathrm{Yb} \rightarrow \mathrm{Er}$ ET in ZBLAN. The behavior of the Tm $\rightarrow$ Ho ET efficiency exhibited in Fig. 14(b) indicates that the
TABLE V. Fast diffusion and scattering parameters obtained from a best fit of $\eta(\mathrm{ET} 1)$ efficiency versus donor (or acceptor) concentration using Eq. (19).

\begin{tabular}{lccc}
\hline \hline & \multicolumn{3}{c}{ Fast-diffusion-assisted energy transfer } \\
\cline { 2 - 4 } & $\begin{array}{c}\mathrm{Tm} \rightarrow \mathrm{Tm} \\
\text { (cross relaxation) }\end{array}$ & $\begin{array}{c}\mathrm{Tm} \rightarrow \mathrm{Ho} \\
\left({ }^{3} \mathrm{~F}_{4} \rightarrow{ }^{5} \mathrm{I}_{7}\right)\end{array}$ & $\begin{array}{c}\mathrm{Yb} \rightarrow \mathrm{Er}^{\mathrm{a}} \\
\left({ }^{2} \mathrm{~F}_{5 / 2} \rightarrow{ }^{4} \mathrm{I}_{11 / 2}\right)\end{array}$ \\
\hline Diffusion & & & \\
$R_{C}(\AA)$ & 14.5 & 11.2 & 7.2 \\
$c_{0}(\mathrm{~mol} \%)$ & 0.4 & 0.9 & 3.5 \\
$\eta_{0}$ & 0.2 & 0.4 & 0.8 \\
Scattering & & & \\
$R_{C}(\AA)$ & - & 5.7 & 4.3 \\
$c_{0}(\mathrm{~mol} \%)$ & - & 7.0 & 16.3 \\
\hline \hline
\end{tabular}

${ }^{a}$ Data obtained from Ref. 8.

fast excitation diffusion is limited by a critical acceptor (Ho) concentration similar to what happens in the $\mathrm{Yb} \rightarrow$ Er case. Assuming the existence of a critical distance $\left(R_{C 1}\right)$ between donors for the fast excitation diffusion and a critical distance $\left(R_{C 2}\right)$ for the excitation scattering, the efficiency of ET1 can be predicted considering that (i) the fast excitation diffusion mechanism has $\eta_{\text {diffusion }}=1$ for donors separated by the distance $R \leqslant R_{C_{1}}$ and $\eta_{\text {diffusion }}=\eta_{0}$ for those having $R>R_{C_{1}}$ and (ii) the fast excitation scattering mechanism has $\eta_{\text {scatter }}=1$ for donors having an acceptor ion at the distance $R \leqslant R_{C_{2}}$ and $\eta_{\text {scatter }}=0$ if $R>R_{C_{2}}$.

Assuming a random distribution between donor and acceptor ions in the ZBLAN matrix, we can calculate the fraction of donor (or acceptor) ions that have another neighbor donor (or acceptor) placed at the distance between $R$ and $R$ $+d R$. Using the same theoretical procedure done in the previous work to calculate the ET1 efficiency as a function of donor and acceptor concentrations involving the critical radii $R_{C_{1}}$ and $R_{C_{2}}{ }^{8}$ we obtained $\eta$ given by

$$
\eta=\left[1-\left(1-\eta_{0}\right) \exp \left(-\frac{c_{D}}{c_{I}}\right)\right] \exp \left(-\frac{c_{A}}{c_{2}}\right),
$$

where $c_{D}$ and $c_{A}$ are the donor and acceptor concentrations, respectively. $c_{1}$ is the critical concentration of donors for fast excitation diffusion and $c_{2}$ is the critical concentration of acceptors for fast excitation scattering. They are given by

$$
c_{1}=\frac{3}{4 \pi R_{C_{1}}^{3}}, \quad c_{2}=\frac{3}{4 \pi R_{C_{2}}^{3}} .
$$

Equation (19) can be used as a fitting function of ET1 efficiency for the two cases investigated: (i) the donor concentration variation and acceptor concentration fixed at $1 \mathrm{~mol} \%$ and (ii) the acceptor concentration variation and donor concentration fixed at $1 \mathrm{~mol} \%$. The solid and dashed lines in Figs. 14(a) and 14(b) represent the best fits using Eq. (19). The values of the critical radius $\left(R_{C}\right)$, critical concentration $\left(c_{0}\right)$, and efficiency $\eta_{0}$ (the fast excitation diffusion efficiency part independent of $D$ and $A$ concentrations) for the Tm-Tm CR, Tm-Ho ET, and Yb-Er ET (for comparison) are shown in Table V. We observed that the exciton diffusion mechanism dominates the Tm-Tm CR and Tm-Ho ET. In our previous work we have observed an analogous behavior 
in the $\mathrm{Yb} \rightarrow$ Er ET as shown in Fig. 14(a) and by the data of Table V. However the critical distance for fast excitation diffusion follows the inequality order $R_{C_{1}}$ (Tm-Tm CR) $>R_{C_{1}}$ (Tm-Ho ET) $>R_{C_{1}}(\mathrm{Yb}-\mathrm{Er} \mathrm{ET})$, which indicates that the fast excitation diffusion that occurs in the $\mathrm{Tm} \rightarrow \mathrm{Tm}$ cross relaxation involving the ${ }^{3} \mathrm{H}_{4}$ state is more dependent on the donor concentration than is observed in the $\mathrm{Yb} \rightarrow$ Er energy transfer in ZBLAN $\left(R_{C_{1}}=7.2 \AA\right)$.

The main conclusion is that the energy transfer process involving the ${ }^{3} \mathrm{H}_{4}$ and ${ }^{3} \mathrm{~F}_{4}$ of $\mathrm{Tm}^{3+}$ in Tm:Ho:ZBLAN glasses occurs in a regime of fast excitation diffusion followed by direct energy transfer. The fast excitation diffusion leads to two distinct types of $D^{*}-A$ interaction according to the total concentration of lanthanide ions in the host. For the case of the ${ }^{3} \mathrm{H}_{4}$ excited state, the Inokuti-Hirayama solution dominates the ET process (or $I>T$ ) if the total lanthanide concentration is below $6 \mathrm{~mol} \%$ (the localized $D^{*}-A$ interaction dominates the ET process for the highest concentrations). In the case of the ${ }^{3} \mathrm{~F}_{4}$ excited state we observed that $I>T$ for a total lanthanide concentration below $3 \mathrm{~mol} \%$. However, the fast excitation diffusion shows some differences when comparing the ET1 efficiency for Tm-Tm CR and $\mathrm{Tm} \rightarrow$ Ho ET. The fast excitation diffusion observed in the Tm-Ho ET process exhibits a scattering effect which increases with $\mathrm{Ho}^{3+}$ concentration with a critical radius of $5.7 \AA$ similar to what was observed in the case of $\mathrm{Yb} \rightarrow \mathrm{Er}$ energy transfer $\left(R_{C}=4.3 \AA\right)$. Nevertheless, no scattering effects on the fast excitation diffusion were observed in the Tm-Tm cross-relaxation process. In this case, ET1 efficiency exhibits a similar Tm concentration dependence as was observed for the case of $\mathrm{Tm} \rightarrow \mathrm{Ho}$ ET, however with a slight increase of the fast excitation diffusion critical radius $\left(R_{C}=14.5 \AA\right)$. Based on our previous report, ${ }^{8}$ it was demonstrated again, in the present work, that the method of analyzing the time dependence of the luminescence from the acceptor viewpoint is an important tool to investigate the mechanism of the energy transfer among rare-earth ions in solids.

\section{ACKNOWLEDGMENTS}

The authors thank FAPESP (Grants No. 1995/4166-0 and No. 2000/10986-0) and CNPq for financial support. One of the authors (L.D.d.V.) thanks FAPESP for fellowship No. 2000/06798-4.

${ }^{1}$ J. Lucas, F. Smektala, and J. Adam, J. Fluorine Chem. 114, 113 (2002).

${ }^{2}$ J. Adam, J. Non-Cryst. Solids 287, 401 (2001).

${ }^{3} \mathrm{~J}$. Adam, in Advanced Inorganic Fluorides: Synthesis, Characterization and Applications, edited by T. Nakajima, B. Zemva, and A. Tressaud (Elsevier, Amsterdam, 2000), p. 235.

${ }^{4}$ D. Bayart, P. Baniel, A. Bergonzo, J. Y. Boniort, P. Bousselet, L. Gasca, D. Hamoir, F. Leplingard, A. Le Sauze, P. Nouchi, F. Roy, and P. Sillard, Electron. Lett. 36, 1569 (2000).

${ }^{5}$ M. Yamada, T. Kanamori, Y. Ohishi, M. Shimizu, Y. Terunuma, S. Sato, and S. Sudo, IEEE Photonics Technol. Lett. 9, 321 (1997).

${ }^{6}$ Y. Miyajima, T. Komukai, T. Sugawa, and T. Yamamoto, Opt. Fiber Technol. 1, 35 (1994).

${ }^{7}$ M. Inokuti and F. Hirayama, J. Chem. Phys. 43, 1978 (1965).

${ }^{8}$ L. D. da Vila, L. Gomes, L. V. G. Tarelho, S. J. L. Ribeiro, and Y. Messaddeq, J. Appl. Phys. 93, 3873 (2003).

${ }^{9}$ L. V. G. Tarelho, L. Gomes, and I. M. Ranieri, Phys. Rev. B 56, 14344 (1997).

${ }^{10}$ Y. Chen and F. Auzel, J. Non-Cryst. Solids 184, 278 (1995).

${ }^{11}$ R. C. Powell, in Physics of Solid-State Laser Materials, edited by R. C. Powell (Springer, New York, 1998), Chap. 5. 